\title{
The Undistinguished Scholar of the Amish, Werner Enninger, -or- Has the Time Yet Come for Rigorous Theory in Amish Studies?
}

\author{
Cory Anderson ${ }^{1}$ \\ Visiting Assistant Professor of Sociology and Geography \\ Department of Society \& Environment \\ Truman State University
}

\begin{abstract}
Werner Enninger embodies the highest standards of methodological rigor and theoretical insight in Amish studies, and this article synthesizes his 30-some publications written in English.

Enninger was a socio-linguist from Germany who conducted field research in Delaware in the 1970s and published intensely in the 1980s. His mixed methods address common hurdles field researchers face and offer meticulously detailed qualitative and quantitative data. Enninger's theory can be organized around a social system model that fuses structural functionalism and symbolic interactionism. Within the model, he proposes a four-part superstructure-(1) core, group-defining values, namely, religious community and separation, (2) are realized in concrete norms in timeless (e.g. New Testament) and time-specific (e.g. Ordnung) ways (3) that are internalized, (4) producing an orderly role system. The role system is accessible to system actors, who assume roles through identifiable symbols (role attributes), notably, dress configurations. Mutual identification of alter distributes role privileges in the ensuing interaction and triggers language choice. The enactment of roles defines the social situation. Social situations of central importance to the brotherhood have fixed roles that are assumed and ascribed, with strong sanctions for deviance. Peripheral social situations permit greater role making, where roles are negotiated, ascribed statuses are reduced, and social sanctions are fewer. Peripheral social situations are the primary source for social change. Enninger's work is not for the faint-of-mind or impatient, yet provides a much-needed source of inspiration to strengthen future Amish studies research, theoretically and methodologically.
\end{abstract}

\section{Keywords}

Ethnography of communication; Grooming and garment patterns; Dress; Pennsylvania German; Amish education; Amish ritual; Ascribed status; Role theory; Semiotics; Sociolinuistics; Structural functionalism; Symbolic interactionism; Superstructure; University of Essen; KarlHeinz Wandt; Joachim Raith; Dover, Deleware, Amish

\section{Acknowledgement}

Gratitude is expressed to Erik Deetz, a spring 2017 Truman State University research assistant, who reproduced Werner Enninger's original figures for this article. 


\section{Introduction}

Ask a contemporary scholar of the Amish what his take is on Werner Enninger's workor even a passing summary as to Enninger's contributions - and you are likely to get the response, "Who's that?” if not just a blank stare. (I know, for I have tried many times.) The scholars passing through Amish studies are many, and few have contributed sustained research, let alone become in-house names. So, then, who is Werner Enninger to even ask?

Shortly put, the University of Essen's late emeritus professor Werner Enninger (19312016) was one of the most prolific, most rigorously methodological, and most theoretically meticulous scholars to undertake sustained study of the Amish. Between 1979 and 1994-the height of his productivity - he published no fewer than 30 Amish-themed peer reviewed journal articles, book chapters, and academic books in English - and that is to say nothing of his many Amish-themed German-language publications and conference papers, plus his beyond-Amishstudies theory publications built from his Amish research, plus his editorship of seven volumes during this span, and, plus, several publications after 1994, including Amish studies' only recent annotated bibliography (Enninger 2002).

Werner Enninger's research was multifaceted, yet remarkably without sacrificing empirical and theoretical rigor, as has been the familiar cost with the frequent generalist approaches to Amish research. The two topics over which he most concertedly mused were Amish language and Amish dress (as a nonverbal communication system), fitting given his intellectual residency in socio-linguistics and semiotics. However, other writings evidence interdisciplinary inclinations toward cultural anthropology, interactionist sociology, and literature. He further wrote about Amish understandings of time and ethnicity, the social dynamics of the Amish school, ethics in participant observation, Amish and modernity prior to the theory's popularity in Amish studies, and the rituals of the church service.

For all of his thoughtful contributions, Enninger's influence on Amish studies - set alongside the big rigs - must be placed on a kitchen scale to measure its significance. Not only are citations to his work nearly zero, but the multi-topic tomes Amish scholars cite with habitAmish Society [4th ed.], Riddle of Amish Culture, The Amish, and Amish Paradox-each refer to no more than four of his authored works (four, one, one, and zero, respectively) amidst a sea of other citations. When they do cite Enninger, they make no mention of his theoretical insights, findings, or methods, not even in areas where his contributions are most profound: clothing, language, and social system functionality. Scholars of linguistics demonstrate only a slightly greater awareness of Enninger's ideas. Steven Keiser and Mark Louden, who have both recently published substantial capstone works about Pennsylvania Dutch among the plain people (Keiser 2012; Louden 2016), make very little reference to Enninger's 20-some pieces in English (and probably that many if not more written in German). 
Certainly, many scholars across history have been forgotten without damage to a field's progress. In this article, I argue that forgetting Enninger is a tragedy, a miscarriage of the Amish studies Meidung — and has been a tragedy for the past two decades. It is time Enninger be given an honorary chair among us. Though not without flaws, his work is a model for the kind of scholarly activity we ought to engage in as we investigate that ethno-religious social phenomenon we call “Amish.” For future generations of Amish and plain Anabaptist scholars, he should be a prime role model.

My reasons for advocating Enninger are four-fold. First, Enninger took others' propositions and subjected them to scientific scrutiny, overturning (or at least questioning) prevailing conclusions. Putting it succinctly, he debated, something Amish studies has rarely done. Either we are too nice to debate or too mean to let others publish alternatives - certainly alternatives exist. Second, Enninger addressed topics of general scholarly interest, cumulatively building on others' work by pushing beyond superficial generalizations to more nuanced conclusions (and inconclusions). Third, Enninger's research was unquestionably theory-driven; he labored to introduce broader theoretical concepts, then applied them to the Amish case. Out of his research, he contributed back to broader theory. Fourth, Enninger's qualitative analysis was self-scrutinizing, ethical, and surprisingly replicable, raising the bar for qualitative study among the Amish, which has too long either consisted of anecdotes falsely labeled participant observation / ethnography or has been at the mercy of the key informant approach. Enninger's qualitative methods are systematic and value-neutral. After reading Enninger, the reader is left with a refreshing confidence that his conclusions were derived from data developed in ways transcending investigator preconceptions.

My fear in summarizing Enninger's work is in doing it an injustice in both not capturing the delightful specificity of his writing (some call it "wordy" though I would call it judiciously worded and free from cliché) and in not summarizing with sufficient comprehension the fullness of his theory. His work will be addressed first methodologically, then theoretically, demonstrating along the way how he models an ideal Amish studies scholar in his (1) engagement with theory, at both macro and micro levels, (2) willingness to debate and overturn false conclusions with data, (3) advancement of past research to more nuanced conclusions, and (4) methodological rigor. One important note I wish to add: I often speak of "Enninger" when at times Enninger has co-authors, such as his mentees and collaborators Joachim Raith and KarlHeinz Wandt. I do not wish to detract from others' contributions, yet am here focusing on Enninger as lead scholar and his ideas as a cohesive body across publications.

\section{The Life of Werner Enninger}

Although the goal of this article is to introduce Enninger the scholar and not Enninger the man, a brief biography is fitting. Werner Enninger was born in 1931 in Germany, just young enough to be spared an otherwise most-certain drafting into the National Socialist military during the 1940s. Coming of age in West Germany in the 1950s, he studied English and sports, then 
taught in a high school. In 1968, he received his Ph.D., and in the 1970s, was called to Essen to help establish a new English department during a West German surge in higher education. At the University of Essen, Enninger drew many doctoral students into research, notably Joachim Raith and Karl-Heinz Wandt, with whom he frequently collaborated (Dow and Wolff 1997, 1-2).

In the 1970s, Enninger received support from five organizations to conduct an extensive study of the Amish in Dover, DE. The organizations included the Deutsche Forschungsgemeinschaft, the Minister für Wissenschaft und Forschung des Landes Nordrhein-Westfalen, the University of Delaware, the University of Essen Gesamthochschule, and the John F. Kennedy Institute at Berlin. With these grants, he coordinated a 35-member Essen-Delaware Amish Project Team (EDAPT), which included eight faculty members (including himself) and 27 students involved at one time or another (Enninger and Essen-Delaware Amish Project Team 1985, 23). The main research period spanned from 1974 to 1978, with the most intensive datagathering occurring over eight months from mid-1977 to early 1978 (Enninger 1980b, p. 349; 1982, 87; 1984d, 67). His time in Delaware was facilitated by an adjunct appointment at the University of Delaware. Meanwhile, his closest collaborators-Raith and Wandt-took forays into Lancaster County, PA, where they expanded (Raith 1980; Wandt 1988) Enninger's Delaware project. In the 1990s, James Dow of Iowa State University, whose work rubbed shoulders with Enninger's — e.g. Dow (1986; 1988)—brought Enninger to the Midwest, where several major Midwestern universities jointly hosted Enninger as an International Scholar in Residence in the mid-1990s (Dow and Wolff 1997, 2).

\section{Figure 1: Werner Enninger and University of Essen Colleague Michèle Wolff}

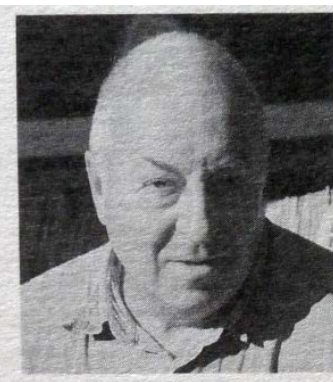

Werner Enninger

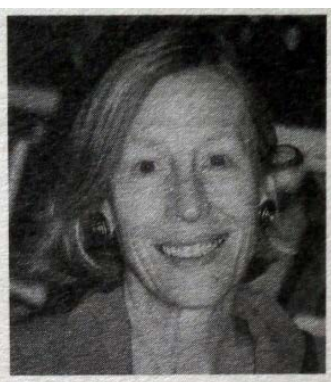

Michèle (Bertin)

Wolff

Werner Enninger was born in Essen where he received his elementary and secos attended the universities of Cologne and $\mathrm{E}$ Ph.D. in linguistics. In February 1997 he will

Inside cover of the January 1997 Pennsylvania Mennonite Heritage, Vol. 20, Issue 1. Used with permission.

Through the 1980s and into his Midwest scholar-in-residence position, Enninger coedited what may have been the closest thing to a pre-JAPAS academic journal for Amish and plain Anabaptist studies: the Internal and External Perspectives on Amish and Mennonite Life series, which contained four volumes released in 1984, 1986, 1988, and 1994, with roughly ten 
empirical articles each. The volumes were compiled from small conferences. Enninger edited the first volume alone (1984), co-edited the second and third with Raith and Wandt (1986; 1988), and co-edited the fourth with Dow and Raith (1994). Among Amish studies' more familiar names in this multi-disciplinary series are-alphabetically_-Hostetler, Huntington, Luthy, Meyers, and Olshan, plus a few peculiar but delightful pieces including then-Beachy Amish-Mennonite convert Fritz Plancke's work on plain dress, Henry Troyer's foretelling work on occupational changes in Holmes County, Annamaria Geiger's communicative contrasts of Old Order and evangelical religious expression, and Anna Francis Wenger's elucidation of Amish health care practices. The volumes are unfortunately under-cited, perhaps due to the small print run and their consequent rarity. Enninger also helped compile a volume of technical language studies (Burridge and Enninger 1992), which included works both of his closest colleagues (e.g. Raith and Wolff) and of other emerging and established scholars of Pennsylvania Dutch (e.g. Moelleken, Louden, Huffines, and Van Ness). Enninger retired in 1997.

\section{The Methodology of Werner Enninger}

Werner Enninger's science is precedent-setting. His largely qualitative methodology is satisfyingly empirical, due largely to its surprising replicability and its logical justification. How does he manage this feat? The bane of Amish studies has long been that Amish shy from the nagging inquiries of formal researchers, especially surveys that treat collectively conferring cultures as if atomized opinions. Enninger attempted surveys in a pilot study, and the Amish reaction only "confirmed the well-documented reticence of the members of this religious group to cooperate with outsiders [...] which led to the conclusion that 'statistical' correlations could neither be based on a random nor a judgment sample” (Enninger and Wandt 1979, p. 53).

Faced with the obstacle of Amish reticence to be studied, Enninger turned to less invasive mixed methods, a tactic-of-necessity that not only provided data more convincing than survey data but also greatly broadened his scope of evidence. Among Enninger's methodological strategies were participant observation and ethnography; content analysis of Amish publications; language interviews; and informal, unstructured interviews, among other strategies.

The focus of Enninger's methodology is in sign systems, the window to any culture. Enninger reasons that culture-as an imperceptible phenomenon-nonetheless demands signification, for culture is shared, and to share is to communicate:

If [cultural] knowledge were only stored in the brain of autonomous individuals and neither fixed in sign-repertoires nor signitively mediated in interaction, it could be neither shared cultural knowledge, nor could it become effective in interaction, nor could it be reconstructed by a culture-external analyst [...] social reality is objectified in sign-systems and re-subjectified in text-encoding and text-decoding processes. (Enninger 1986c, p. 116)

Sign-systems, then, are a logical focal point in understanding Amish culture, and Enninger's multiple methodological strategies pull together a smorgasbord of evidence. 
Enninger's data includes oral language, written language (ethnic texts) including typographical repertoires (e.g. Gothic font), song transcription, clothing articles, cultural artifacts like building architecture and transportation vessels, body motions (especially ritual motions), and even silence itself (Enninger 1985), or absence of cultural themes prevalent elsewhere. Within Enninger's publications, a reader will encounter flow charts, tables cataloging social action, musical staffs with notation, lists of linguistic information, rich ethnographic descriptions, population pyramids, graphs of role distributions, tables of role-specific language skills and varieties in use, settlement and regional maps, drawings of cultural artifacts, and theoretical models - combinations of these and other data presentations are more often than not paired in single pieces. Frankly, the sheer amount of replicable data is overwhelming but welcome.

Of all methods employed, Enninger gives the most attention to explaining participant observation. With few examples of strong methodological reflection treating data collection among the Amish, Enninger's effort to detail his strategies is needed. An article by Enninger and Wandt (1983) reflecting on ethnographic methodology identifies three methodological challenges particular to the Amish.

The first concerns community access and data collection, a familiar challenge to wouldbe researchers of the Amish. Participant observation is inherently difficult due to the closed Amish networks (few access points), no coincidence given the core value of separation and an oft-repeated narrative of a martyrdom past. Outsiders must build trust slowly. Enninger writes:

The progression from the undisguised suspicion of being a 'spy' to an invitation to church ('If you do not want to preach'), to the status of a trustworthy linguistic field worker took months; and ninety percent of the more valuable data were collected in the last of eight months spread out over four years. (Enninger 1982, 118)

Even once networks are penetrated, two problems exist. First, the standard tools of field researchers - voice recording devices, cameras, and video recorders, perhaps also portable computers in recent years - are almost certain to raise the Amishman's cautiousness if not complete withdrawal. Enninger's list of problematic research tools and protocols is hardly complete. For example, Adkins (2011) later identified technical bureaucratic jargon common in IRB informed consent forms and surveys as similarly alienating. All of this suggests that, even more than some reticence against technology, the typical Amishman is hesitant to "go on record"-be it his voice captured word-for-word, his image presented in a photograph, or his contribution to any activity involving the government-like bureaucratic jargon of a big university - for, who is he to solely represent the unified voice of the community to the world? Enninger suggests that pencil-and-paper note-taking is the least intrusive mode of data collection, even though it presents limits to transcript analysis. "In this culture," he concludes, "the choice the field worker has is to work on the basis of the obtainable data, or to gain no insight at all” (Enninger 1987b, pp. 149-150). 
With tools in hand and community access opened, the researcher must still be able to observe natural social events unimpeded by the researcher's presence. Inconspicuous observation is difficult because few natural roles exist for outsiders, and to take the role of "researcher" may produce unnatural situations. Enninger recommends resolving this dilemma by taking one of a few natural outsider roles, including taxi driver, customer, or expert in something they have interest in (e.g. German language and culture, in Enninger's case). With the increasingly pervious Amish networks today, more roles could no doubt be added to this list, as illustrated with Denise Reiling's (2002) role as mental health expert in the midst of a counseling conflict or Natalie Jolly's (2014; 2017) as assistant to a midwife_-or, looking back to Kollmorgen's Great Depression-era field researchers, Charles Loomis's role as a farmhand (Loomis 1979). The ultimate goal is not to hide one's role as researcher but hope that the researcher role can recede and the natural role move to the fore. Enninger observes some closed social institutions provide basically no opportunity for the outsider to take on a natural role-notably the school setting (Enninger 1987b) — an observation substantiated by Andrea Fishman's (1988) experience: her school observations were suddenly cut off when her informant told her some parents felt it was enough and that it was creating discomfort.

A final data-collection hurdle is apart from the research subject. As with other long-term participant observation studies, the investigator may find funding and approval difficult to obtain due to the vagueness of measures, hypotheses to be verified or falsified, and instruments. Furthermore, only fuzzy hopes can be offered as to when quality ethnographic data will be obtained. All-in-all, such open-ended studies have difficulty garnering enthusiastic support.

A second difficulty of Amish research according to Enninger is psychological in nature. In particular, it is the researcher's superimposition of personal biases and frames of reference on research and interaction, as with the treatment of the Amish as anything from people who maintain quaint customs of the past to secretive, patriarchal child molesters, or in some other way "exotic, bizarre, or even irrational” (p. 34)—or, contrariwise, a rationalized, living moralistic lesson. Such simplistic frames show up not only in mass media, but too often in scholarship as well. In his Dover study, two researchers lived on an Amish farm while a third commuted daily. A third party reviewed the field notes of these researchers and suggested that the two live-ins faced high initial interactional frustration, but observational sensitivity increased alongside growing interactional competence, moving from guests to quasi-family members. Meanwhile, the commuting researcher-daily living in two worlds-expressed interactional irritation throughout the study. Beyond the suggestion that immersion permits greater empathy and understanding, Enninger leaves the larger question of pre-existing frameworks open-ended, a question for future researchers to explore further.

The third difficulty of Amish research pertains to ethics. The researcher's total immersion in participant observation raises interesting questions: what does the researcher do with information that could harm the subject? Being a quasi-member of the community, Amish may confide with the researcher (e.g. grievances or negative sanctions), secrets he would not share 
with his own people. Does the researcher honor the trust granted his quasi-membership, or does he have an obligation to report all observations to the scientific community? Enninger asserts a definitive answer: while sensitive information may be included in field notes, data analysis must not only convert raw data to valid data but also filter data. After all, the researcher can only justify his invasion into the private, sensitive realm of a semi-secluded people as his research contributes positively to the community. Enninger gives the example of how he tried at every opportunity to convince the Amish that their Dutch is not impure but is adapting and surviving.

This subject of research ethics is sticky-especially when incriminating information is discovered-but remains relevant for today. Voelz (2016) recently touched on such ethics for exAmish memoirists: is it an ethical violation for authors to move beyond re-telling their own experiences and surmise or reveal incriminating third-party details? Reiling and Nusbaumer (1997) tell of an interesting case where the Amish of Northern Indiana acquiesced to locals framing their youth as having a "drug problem," but when the framing became too invasive, the Amish resisted this label.

Much more could be written about Enninger's methodology_in particular his linguistic research - but this suffices as the necessary introduction to understanding how he developed his theory of the Amish, to which we now turn.

\section{Werner Enninger's Theory of the Amish}

While Enninger dabbles with symbolic interactionism, he is foremost a structural functionalist in his Amish research. In that fact alone, he differs little from the implicitly assumed theoretical moorings of the bulk of Amish scholars. Yet, Enninger's functionalism restores hope for the explanative power of a theory that is often reduced to, "What you see exists because it serves a function, and the function is...," with a set of explanations as to "why" that satisfies the acceptable logic of an outsider (etic perspective) (Billig and Zook 2017). Instead, Enninger's task is to explain the emic (insider's logic) perspective-why the social system exists, how it reproduces itself, what latent functions exist, and how the social system adapts to social change. While he feels obligated to honor Amish trust by not disclosing incriminating data, he does not in turn valorize the Amish, moralizing the social system with lessons for non-Amish readers. His functionalism is value-free. He thus stands in the Charles Loomis (1960) tradition (Donnermeyer 2017) and skirts Marc Olshan's (1981) then-current rational choice alternative, for Enninger appears unconvinced that the Amish are so self-consciously rational, not that they do not rationalize, but that it has taken on a routinized, predictable form that in itself is properly latent.

The moorings of over a decade of field research, analysis, theorizing, and publishing can be found in a piece released the first year_-1979 — of his Dover, DE, study publishing streak. In "Social Roles and Language Choice in an Old Order Amish Community” published in Sociologia Internationalis (Enninger and Wandt 1979) — a journal whose editor was also at the University of Essen-Enninger poses a question out of his interest in the Amish as trilingual: for 
the three language varieties at Amish disposal, in what situations do they use which language? Enninger briefly visits the only prior work about Amish language choice: Frey's (1945) "Amish Triple Talk.” He agrees with Frey, that language choice is situational, although his field research does not agree with Frey's evasive suggestion that “occasion” (e.g. school, the home, or the church service) determines language selection. In field research, Enninger noted inconsistencies in language selection if "occasion” or "place” was the definer, even situations where the language ultimately used was not clear during an interaction's opening. He suggests an alternative, that roles determine language selection. This begs a two-part question: how do Amishmen determine roles, and how much role clarity / agreement actually exists?

The Amish literature yielded no theory to answer his questions, so he turns to broader theory to apply to the Amish case. The end result not only addresses language use and roles but is a total theory of the Amish social action system, addressing both macro and micro social structures and the changes of both, exploring grooming and garment practices, buggy styles, literature, conceptions of time, social institutions, ritual and music, and other topics. Twice he presents the theory diagram of Figure 2, first in his "Social Roles and Language Choice..." article referenced above (Enninger and Wandt 1979, p. 58) and then again in his short book about the Amish church service (Enninger and Raith 1982, p. 88). Although nearly all of his research can be couched in this theory, he seems somewhat reticent about reintroducing its tenets in most publications, preferring to manage a topic at hand in itself. Furthermore, he seems restless with exactly how all the pieces fit together, hence some modifications between 1979 and 1982, as well as a competing (simplified) alternative model that also incorporates changes through time (introduced later). The over-arching theory represented in Figure 2 is the only comprehensive theory he provided, and, despite its limitations, will be used here to organize his findings.

\section{The Superstructure (“Überbau”)}

Stepping back from the question of roles, Enninger first conceptualizes the superstructure that is the justification for the Amish's existence. The superstructure contains four levels: the centrality of values, forms of behavior (making values concrete), social control (implementing these behaviors), and the role system (the repertoire of roles possible under these internalized values).

\section{Centrality of Values (Level " $b$ "3 in Figure 2)}

The superstructure begins with values, that is, the Amish only exist because they, like other cultures, make sense of society through certain guiding values. Ultimately, values stabilize and reproduce the system. While other publications often present some cherry-picked Amish values in a throw-away introduction, Enninger selectively presents the values of most immediate consequence to their social system and contextualizes them in his theory. 


\section{Figure 2: Enninger's Theory of the Amish Social-Sign System}

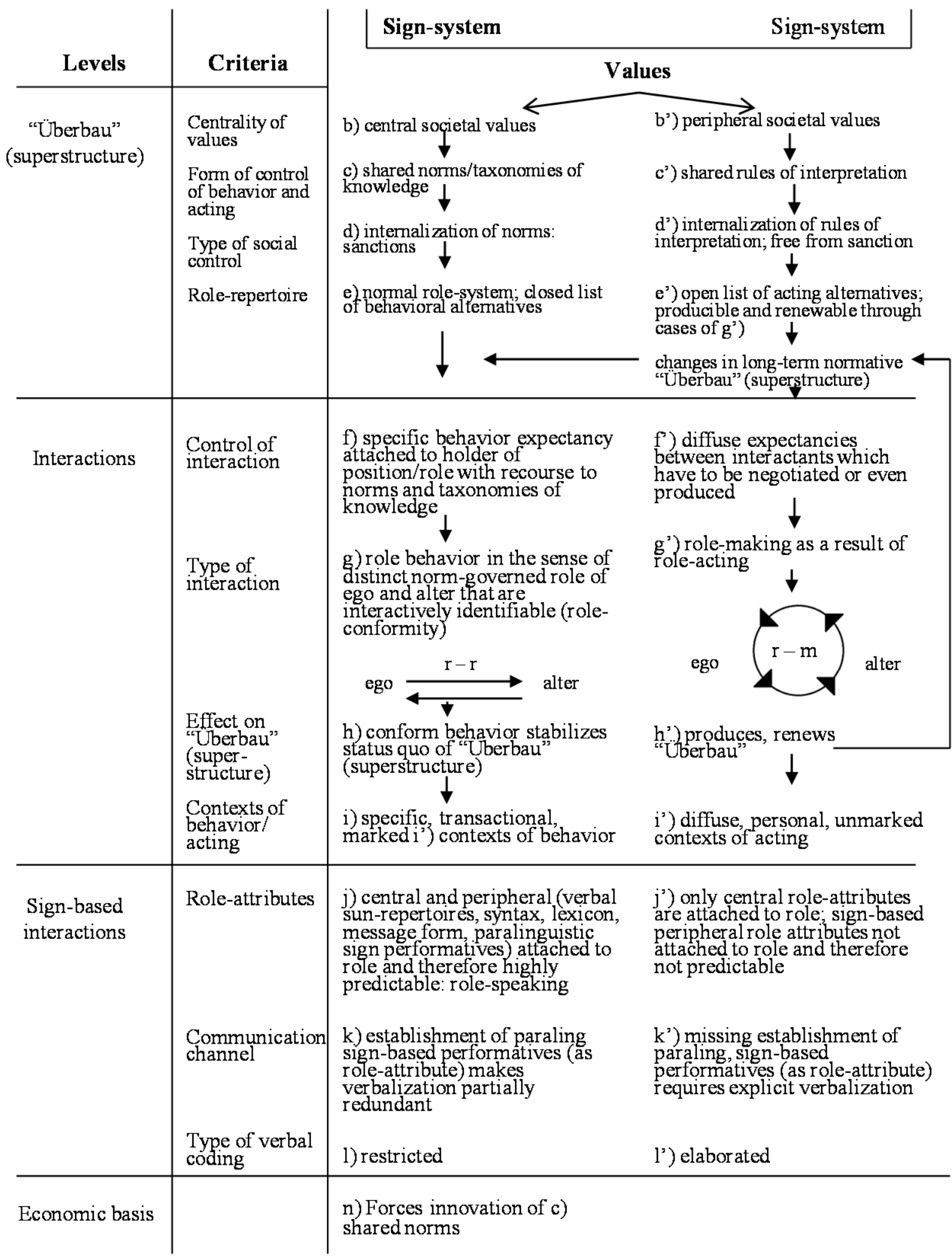


First, the Amish are chiefly a localized, voluntary religious community, a brotherhood, that in all facets of life affirms the "transcendental essence of the collectivity" (Enninger 1988b, p. 168). Not to say that the brotherhood is a perfectly unified entity, but that individuals - if in conflict with the brotherhood-find no respite or resource from the community-specific values (Enninger and Wandt 1979). Salvation is realized through this faithful brotherhood, not through the mediation of an institutionalized church (as with Catholicism) or individual experiences (as with Protestantism).

In [its] historical self-interpretation, the [Amish] community perceives itself as a brotherhood that stands in the tradition of the earliest Christian congregations; this brotherhood of true believers has to live in harmony with God's nature [...]. This idea of the pure brotherhood is in the center of rudimentary Anabaptist theology. The term Gmee reflects the identity of the religious brotherhood, of their congregation in the church service, and of the social community (Enninger and Wandt 1982, p. 133).

Though inseparable from the social community, the religious community is what justifies the existence of the social community, not vice versa, for the religious foundation creates a holy community. The focus on holy living precludes elaborate theological texts and discourses, as the separation of religious thought (in theology) and life is not possible, and, where it occurs, is in dangerous detachment from life's concrete pressures or is justifying something that is better justified in example, not argument (Enninger 1988d).

Second, and closely related, the brotherhood must be separate from surrounding society, whatever that society may be. The early Schleitheim Confession suggested a religious movement premised on socially spaced religious separatism, a “we-ness” separate from "their” cosmos. While the religious community is forced to live in the temporal world, they seek to remain separate from it, to be governed by a different master narrative. Continual persecution and the Amman/Reist division further institutionalized this doctrine. Upon migrating to the United States, the Amish maintained separation, not out of resistance to ethnic assimilation but because of the religious precedent to remain separate. The Amish frame their history according to the martyr theme, based on The Martyrs'Mirror. This framing makes sense, as it demands renouncing the world and the ensuing costs (Enninger 1986c 1988d).

Finally, the Amish view of history and important historical events frames much of their outlook on life. This is presented most thoroughly in Enninger's rather late publication-_'The Social Construction of Past, Present, and Future in the Written and Oral Texts of the Old Order Amish: An Ethno-Semiotic Approach to Social Belief”-found in an edited volume of literary anthropology research (Enninger 1988d). In it, he applies two useful frameworks: Alfred Schuetz's (1972[1932]) social constructs of time (Vorwelt, Umwelt, Mitwelt, and Folgewelt, that is, social worlds of predecessors, of one's experienced present reality, of contemporaries one lives concurrent with but does not experience as one's own, and of successors) and Fernand 
Braudel's (1977) time constructs (courte duree, longue duree, and grande duree, that is, time as events, as epochs, and as God's span).

Amish identify five important events in the grande duree: Creation, original sin, Christ's first appearance, Christ's imminent return, and the final establishment of God's Kingdom. While other Christians hold these as important as well, Enninger explains the distinctive Amish views. The most recent event - the coming, death, and resurrection of Christ - is their past focal point, and that Christ's imminent return renders the Enlightenment's progress narrative (the Mitwelt of the Western world) as irrelevant and suspicious in contrast to the demand of living faithfully in the community (the Umwelt). The church's history, including its martyr history, rather lies between Christ's first and second comings in the grande duree, as a cycle of generations denying the Mitwelt and choosing to suffer, be it in martyrdom and persecution or the Americanized adaptation of the suffering theme: bearing life's troubles and sorrows (Enninger 1988d).

\section{Concretization of Norms (Level “c” in Figure 2)}

Values are realized in concrete, recognizable norms, the next level. The most immediate sources for norms include the New Testament, the Dortrecht Confession, and the Ordnung. The first two documents - and other timeless pieces of the grande duree (e.g. hymnals, Menno Simons’ writings, and prayer books) — are set in Gothic fonts, an unchanging then-form (Enninger 1986c 1988d).

Yet, the Amish system of social action is suspended between the unchangeable environment about them (social and natural) and the timeless norms derived from religious texts. Here, the Ordnung and current teachings are of particular interest because they change with and respond to the unalterable environment, defining norms pertinent to any time and place as an extension of fixed religious documents. Ordnung norms that stem from their values include endogamy, farming (or other community-based occupation), non-emphasis on converting outsiders, absolute prohibition and conditional use of many modern technologies especially communication and transportation technologies (limits group-transcending contacts and influence, limits radius of interaction, and prevents the intrusion of the profit motivation in business), and the maintenance of in-group specific languages (Enninger and Wandt 1982, pp. 133-34, 136).

Contemporary texts, such as Young Companion and Family Life, also address the tension between wider context and community. Although they treat concerns of the day, the lessons are timeless: guard against the world and seek advice from the Christian faith and the church. Because these texts affirm somewhat changing contemporary norms and are of recent origin, they are in English and set in Latin fonts, reserving Fraktur and German to central texts (Enninger 1988d).

While the community must operate within the courte duree and make norms in response to its changes, the decisions are temporal and do not affect the grande duree. Given the value 
orientation to the community and the grande duree, the Ordnung, recent texts, and other decisions made in response to the courte duree generally consists of an adoption lag. The Amish are oriented toward offsetting themselves from temporal events to the degree that it does not risk the community's stability. As the courte duree continues shifting, the norms established in response are forgotten as they become irrelevant in the face of new norms (Enninger 1988d; Enninger and Wandt 1979).

Ethnicity is an additional process that made norms out of values. In Europe, as proselytizing became limited to offspring in the face of severe persecution and rural isolation, the religious community became synonymous with a kinship network. Upon moving to America, where persecution was nearly absent, the martyr theme no longer provided continuity, and "the Martyrs' Mirror is now less widely read than owned [...] the ethos' historical continuity of the more recent past tends to be rather constructed in terms of the commonality of biological descent.” Thus, genealogies have been rapidly produced and read. Historical continuity in genealogy creates a sense of coherence and belonging: “...the procreational chain has assumed the status of the predominant category in which historical continuity is perceived" (Enninger 1986c, pp. 126-27). Ethnicity has produced norms of association and practices particular to the biological community.

\section{Social Control / Internalization (Level “d” in Figure 2)}

The next level is internalization, or, social control. Internalization occurs foremost through socialization and secondarily through positive sanctions (e.g. aid and status) and negative sanctions (stigma, confession, and the Meidung). Because of the brotherhood value, group-specific internalization tends to be total, and,

[...] in contrast to Western societies the community (in both its religious and social readings) is furnished with so high values [...] that an individual does not have to be coerced by negative sanctions into an outer compliance with norms, but will of [himself] symbolize the inner acceptance of the higher evaluation of the community. This presupposes a much subtler instrument: that of early and sometimes sub-conscious [...] internalization, which—if effective—renders the repression of deviant behavior through negative sanctions largely redundant. (Enninger 1980a, 54)

The norms and markers of group identity central to community functionality-including a groupspecific language possible because of a membership nearly completely born into the setting (Enninger 1986a) - are internalized through community institutions, including family, church, and school, all domains largely impervious to external influences. Where sanctions are necessary, they are highly informal. The community is responsible for maintaining purity through scrutinized admission to membership and the semi-annual communion table, and community intimacy allows for members to engage in constant and mutual surveillance (Enninger 1986c). 


\section{The Role System (Level “e” in Figure 2)}

If the prior three stages strike the skeptical reader as but microwaved leftovers of the same ideas served up hundreds of time, this is the stage where Enninger's distinguishing contributions emerge. Enninger conceives of Amish society in practice as a repertoire of available roles. Internalization of the value system's concrete norms (as with the New Testament and Ordnung) produces a society where the predictable enactment of norms produces and governs a relatively unchanging repertoire of roles, an orderly system of interactional performances (Enninger and Wandt 1979).

Invoking role theory, Enninger identifies a fundamental debate between symbolic interactionists (ala Victor Turner and George Mead) and structural functionalists (ala Talcott Parsons and Ralf Dahrendorf). Structural functionalism's “conventional” role theory assumes "prefabricated normative patterns [...] which interactants have internalized in the process of a ‘successful' socialization” (Enninger and Wandt 1979, p. 54). Roles are but institutionalized reciprocated expectations. However, in Enninger's field observations, roles were at times uncertain, especially where no predefined role designation existed. This situation fits the symbolic interactionists' conception of role theory, which argues that roles are of-the-moment, negotiated, and modifiable, particular to each situation. Interactionists critique the overly socialized views of structural functionalists, feeling that such a role situation exists only in heavily socialized contexts (i.e. complete consensus or repression). Structural functionalists view interactionists as theorizing in a hypothetical world absent of conformity pressures.

Enninger concludes that the highly integrated Amish social world conforms by-and-large to a structural functionalist understanding: very high socialization and internal role consistency requires but mere identification of another to determine roles. Thus, individuals engage in roletaking, selecting from a commonly shared repertoire of roles in executing social action. Yet, he acknowledges that situations of role uncertainty occasionally arise from peripheral ("diffuse”) social scenarios in Amish life, and this requires — consistent with the interactionist perspectiverole-making. In light of both theories’ potential usefulness, Enninger synthesizes the two into a new definition of roles:

...roles are bundles of expectancies attached to social positions. [...] social positions [that] are constituents of institutionalized and formalized events, have bundles of collective expectancies which are formulated as rights and duties (obligatory expectancies). In such norm-defined events, role partners must identify role expectancies and realize them in role behavior (role conformity). [Alternatively,] social positions [that] are constituents of diffuse non-institutionalized and nonformalized areas of interaction have expectancies [that] are not predefined and specific, but diffuse. Interactants in such diffuse social areas can and must negotiate a pattern of mutual expectancies, or perhaps even produce them (role-making). (Enninger and Wandt 1979, pp. 56-57)

Thus, Enninger defines two social situations, one of role conformity when expectations are known due to socialization—namely, in a social group's central functioning domain — the 
other of role-determining, if not role-making, when expectations are not known-namely, in a social group's peripheral functioning domain. The peripheral domain is represented in Figure 2 by a second set of parallel superstructure levels at the margins of the social group:

b’) peripheral values versus central

c') shared rules of role interpretation instead of role taking,

d') internalization of interpretation rules, which, due to the rules' subjective, ad hoc

negotiation, is free from the sanctions characteristic of norms produced from central values

e') role-making_-acting alternatives, versus pre-fixed roles to take on.

Enninger argues that the Amish social system is so structured and internalized that it serves as a good example of conventional (structural functionalist) role system, this in a theoretical world where the uncertainties of b'-e' were thought to more accurately capture all of social life, a rejection of the "overly socialized" structural functionalist view.

The Parsonian notion of obligatory role-taking due to institutionalized socialization flies in the face of individualization, social atomization, and self-determination ("I make of myself what I want, and can do what I please as long as it does not interfere with what you want to do”). Consequently, it has fallen from grace in Western sociology, arguably due more to political correctness than empiricism. Yet, Enninger's theory is aptly developed from the Amish, a people suspended between an internally totalizing social system and the self-determining society in which they are embedded. From there, the evidence of integration and pre-defined roles may be somewhat more evident in the non-Amish mainstream, to the extent that society makes provision for shared socialized experiences (which occurs to a degree even in America).

Roles that are obligatory, those that are "constituents of institutionalized and formalized events" and are hence important to the social system, must be performed. Optional roles are products of "diffuse non-institutionalized and non-formalized areas of interaction" and may be performed as individuals choose. Obligatory and optional roles are two ends of a continuum demarcating role relations to social events and role centrality. A third role category, forbidden roles are those that must not be performed, either proscribed altogether as outside the community or the performance of an internal role to which one is not entitled. Obligatory roles not performed or forbidden roles performed are subject to negative sanctions. Since positively sanctioned interactional realms are often within the community's familiar structure, consequently, role obligations, options, and restrictions are largely understood and predictable (Enninger 1984a, p. 80; Enninger and Wandt 1979, p. 54; 1982, p. 126).

The value of brotherhood - collectively struggling toward salvation-produces norms that deter internal competition, which is also characteristic of the role system. Hence, roles are ascribed (distributed based on age, gender, and selection by God for the ministry), not achieved (distributed based on effort, ability, strength, education, and wealth). Ascribed roles provide all members with definite and unchallenged role statuses that gradually move up with biological 
age. Stressing ascribed roles also reduces rapid vertical mobility, supporting brotherhood equality and socio-institutional separation (Enninger 1980a; Enninger and Wandt 1979).

\section{The Superstructure: A Brief Summary}

The superstructure is a set of values that are realized through norms, which norms are internalized and ordered into roles. The (b) value, (c) norm, (d) internalization, and (e) role system levels of the superstructure include central (structural functional) and diffuse (symbolic interactionist) systems, the left and right columns of Figure 2. As highly structured as the Amish community is, the central system is of most interest. At this point, Enninger has but described a static social structure, and is not attempting to explain social action or social change. Most of his work, to which we now turn, explains how the superstructure-particularly the role systemgoverns mundane interaction among members, the social action. In addition, he acknowledges (though explains in less detail) how social action in diffuse social realms and among role-makers produces social changes in the superstructure.

\section{The Interactional Domain (Second Tier of Figure 2)}

While the superstructure describes the overarching social structure (tier one of Figure 2), the interactional domain consists of social processes (tier two of Figure 2). Enninger frames it as the instrumental social action system of Max Weber and the symbolic social action system of George Mead, which Enninger argues are theoretical synonyms:

In that they are actions they are assumed to share the element of "subjective sense" (subjektiver Sinn; Weber), which subjective sense is constituted in the actor's preconceived action project (Schütz). Both are social actions in that ego's intended subjective sense is projected towards and in turn modified by the presupposed behaviour of alter. (Enninger 1982, p. 94)

The interactional domain consists of four processes that actualizes the role system day-today. First, prior to interaction, individuals have expectations for what sorts of attributes are associated with certain roles. Second, in an interactional opening, this information is used both to signal the role ego is taking and to identify the role alter is signaling. Third, repeated interactions reproduce, reinforce, and alter the total role system of the superstructure. Fourth, role-taking and unfolding interactions define the social event, which itself distributes the possible roles at the event.

\section{Expected Attributes of Roles (Level "f” in Figure 2)}

Prior to contact, individuals expect that certain symbols will denote given roles; these symbolic representations are "role attributes" and are needed for interaction. Role attributes express a role and conform to the norms expected for the role. The Amish role system privileges several categories of role attributes including fixed (ascribed) attributes —age, sex, marital status - and the internalized and learned-language spoken (PG, AHG, or English), configuration of clothing, buggy style, and even posture. 
Role attribute expectations are widely shared, as individuals have common knowledge of and access to their superstructure. The superstructure's role system determines what functional attributes of roles are. Absent a role system, language or clothing, for example, would hold minimal relevance to interaction, as no expectations exist prior to any given interaction. For the Amish, clarity of and agreement on expected attributes is the consequence of the intensely integrated social system (Enninger and Wandt 1982, p. 127). This is in contrast to mainstream society, where people's fragmented lives create multiple role attribute expectations that could harmonize, compete, require negotiation, or be misunderstood. Enninger's use of the Amish as a case is apt in describing a near-ideal system of agreement, perhaps useful to later researchers who wish to identify shared social processes that are nevertheless convoluted and variable in mass society.

(a) Role attribute expectations: Grooming and garment patterns

For the Amish, grooming and garment patterns (G\&GP) are a foundational nonverbal signifier of roles. What someone wears signals what role he is taking. In a highly integrated society such as the Amish, where face-to-face contact is frequent, the Amish have built an extremely elaborate system of clothing symbols, which nuances are lost on the uninitiated. To illustrate G\&GP's symbolic function, Enninger compares it to linguistic units (Enninger 1979b, pp. 468-472; 1980a, pp. 29-33; 1982, pp. 93-96). This relationship is visualized in Figure 3.

\section{Figure 3: Communicative Parallels between Verbal and Symbolic Elements}

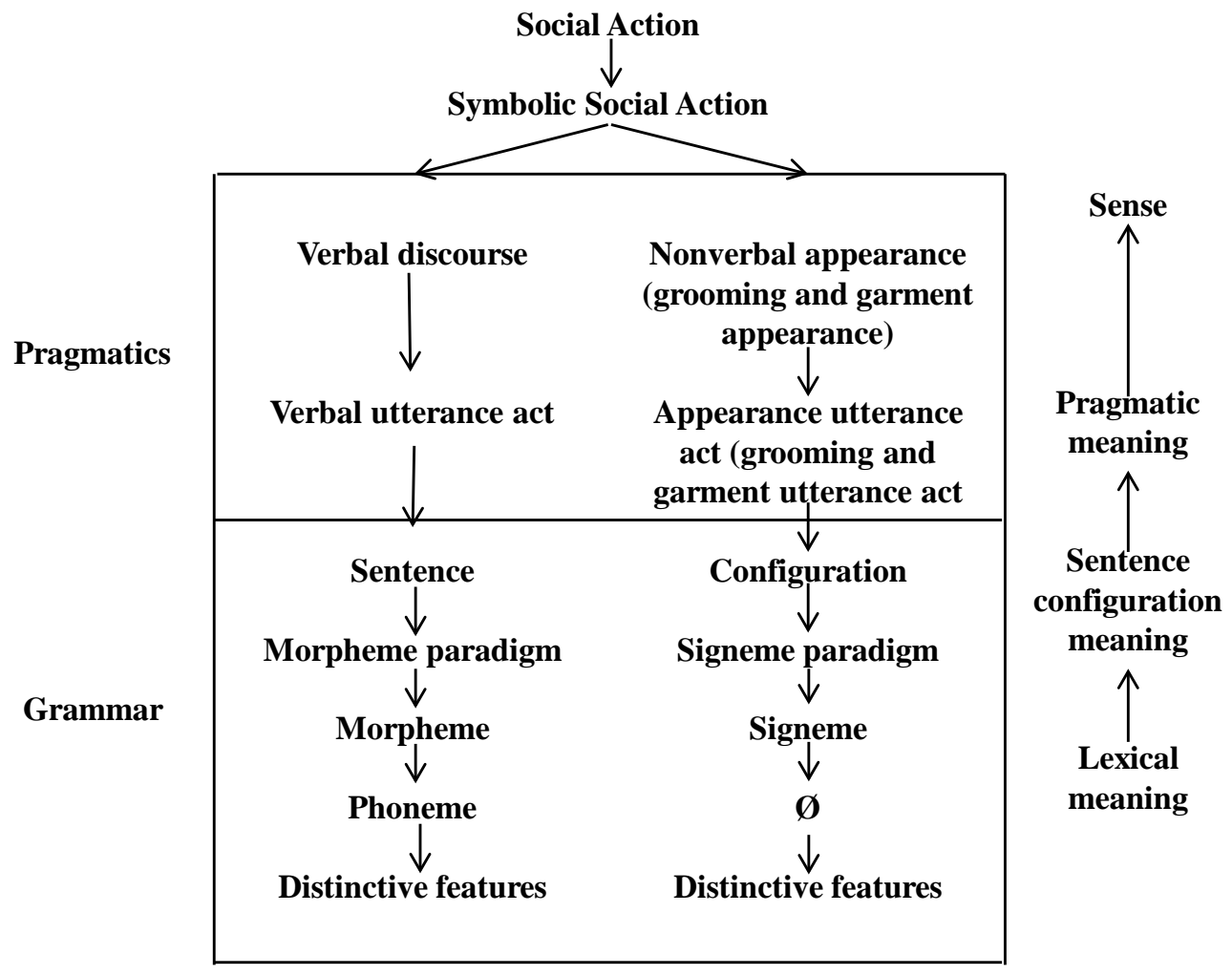


At its base, both language and G\&GPs have distinctive features, the most elementary form of distinguishing a sound-or clothing fragment, e.g. thread, stitch, etc.

At the next higher unit of speech, phonemes - that is, the smallest unit of speech setting apart one word from another, e.g. "m" in "map" sets it apart from tap and sap_Enninger concludes no G\&GPs parallel exists.

The next unit up is morphemes, the smallest grammatical units such as words, e.g. "the" or "hat," or word elements, e.g. a prefix or suffix. The G\&GP parallel are signemes, which could include material, color, shape, texture, transparency, and so forth. Signemes-like morphemes - have lexical meaning, as in, a simple idea.

The next unit up is morpheme paradigms (i.e. any possible morphenes in a given slot). The G\&GP parallel are signeme paradigms. The paradigms are functional slots suggested by the body's anatomy: head, neck, torso, legs, feet, and so forth. The total collection of a given body slot's potential fillers is the signeme paradigm. This concept-like linguistics' morpheme paradigm - is still fairly useless in everyday communication.

When morphemes co-join to create a sensible thought, the result is a sentence. The clothing equivalent is the configuration, that is, a combination of slot fillers-e.g. clothing that goes on the torso, hips-legs, hands, feet, head, and so forth - that holds the symbolic meaning of a role. Just as there are many possible combinations of morphemes - the vast majority of assemblies making no sense_-so are there rules governing what very few configurations of signemes ultimately hold meaning. Configurations include both signemes simultaneously filling slots (e.g. shirt and pants) and signemes layered within a single slot (e.g. coat and shirt).

With this linguistics-based interpretive framework of G\&GPs constructed, Enninger next demonstrates how slot-fillers and configurations (1) have developed from shared norms, and (2) identify individuals with roles (G\&GPs as attributes). The slot "head" serves as a first case. For men, beard styles are attributes of roles that express age, baptism status, and marital status. The beard's conspicuity grows with positions of status, from clean shaven (unbaptized youth) to thin, trimmed beard (baptized youth) to a full Tauferbart (married man) or increased but not full beard (bachelor). The beard is cumulative, with each status implying all prior. Beard length functionally denotes status importance in the community. For example, the bachelor beard is necessarily smaller than the married man's beard. While both are adult men, only the married men propagate the faith, given Amish emphasis on continuity through socializing and retaining offspring versus proselytizing, hence the greater conspicuity of the married man's beard.

For women, their kapps and bonnets denote a similar pattern as men's beards. But what is more, they also denote the social event, something the man's relatively fixed beard cannot. Enninger provides a flow chart to establish headgear relationship to role and situation, which is represented in Figure 4. (Enninger also presented a beard flow chart, but for the sake of space, will not be recreated here.) In public and outside, women wear a uniform bonnet over their kapp, signaling solidarity to the world. When within the social community, women wear kapps of 
ปี
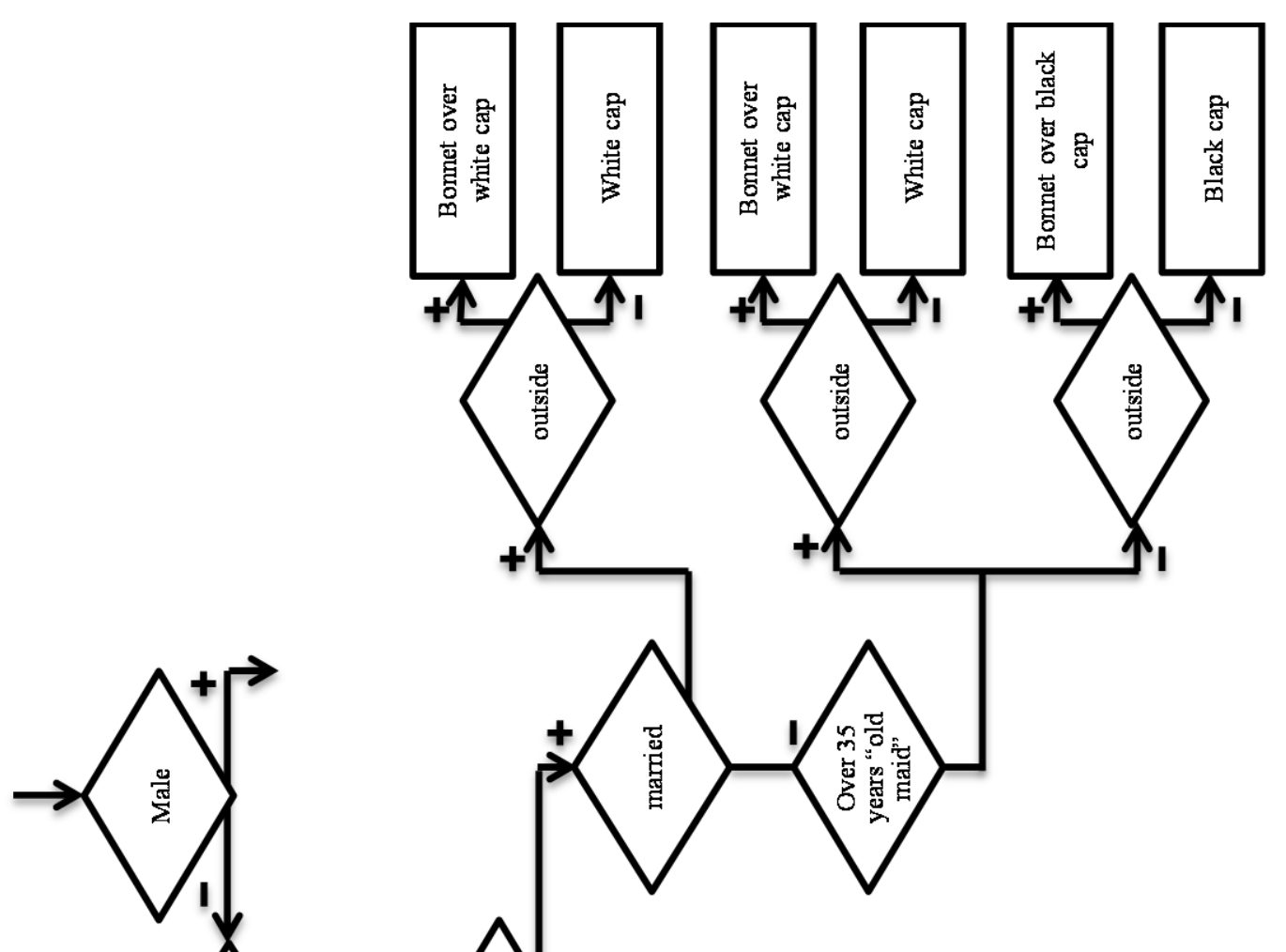

$+2$
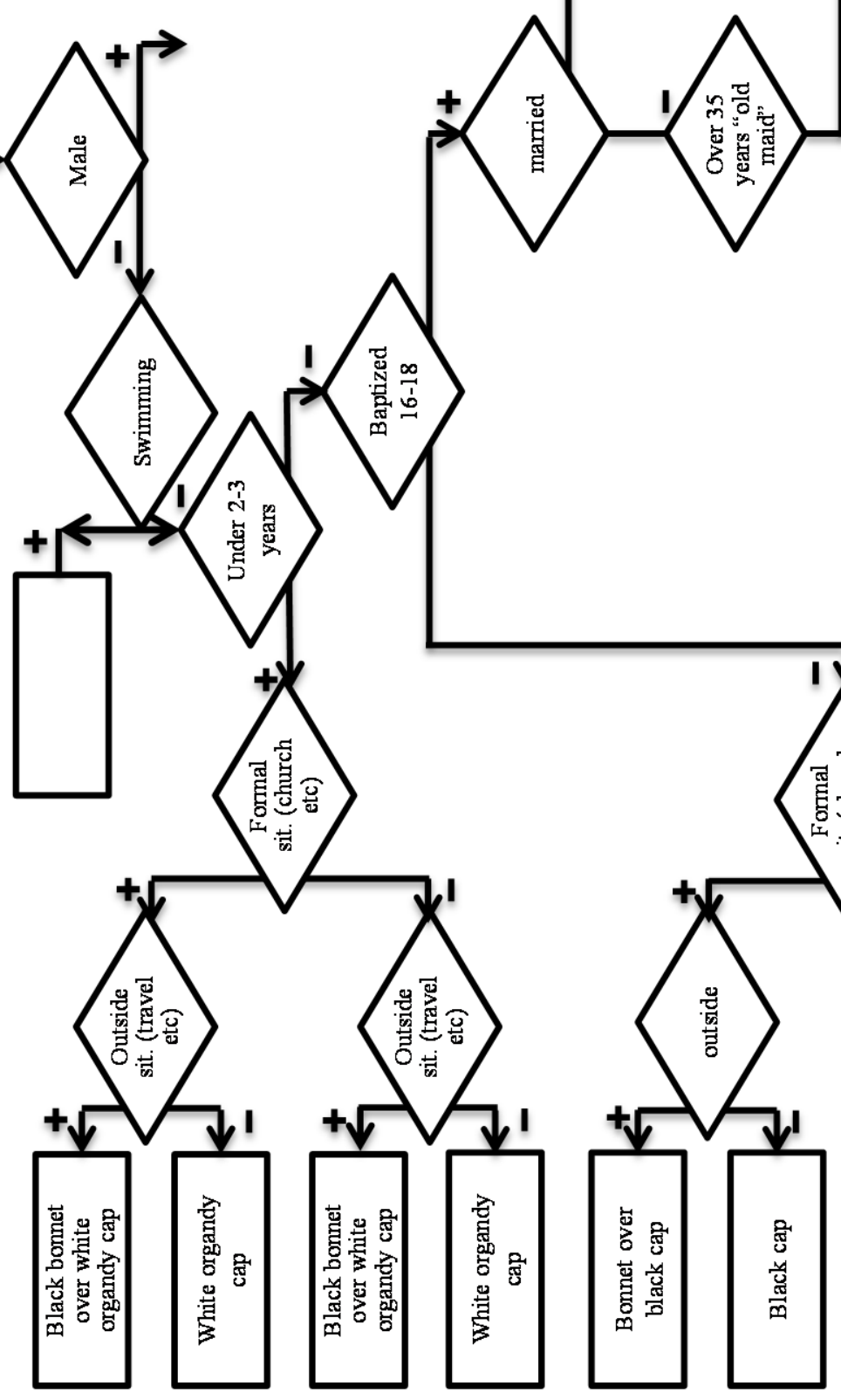

久

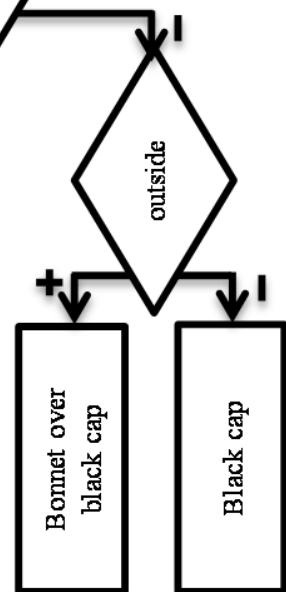


varying styles to signal internal status. Very young girls, married women, and old maids wear white kapps while baptized unmarried youth wear black kapps. Unbaptized children and young people may wear a black kapp or no kapp at all. Enninger explains two status discretions in this pattern. First, the baptized youth girl attains status by having fewer choices, going from no kapp or black kapp to just black kapp, a status shift that is apparent after repeated interactions. Second, while age distinguishes the very young girls from adult women, no kapp signal distinguishes married women and old maids. This absence is explained as, that while the old maids have lower status than married women in this family-centered community, the "white cap is a symbol of brotherly love that glosses over the mild stigma of being single” (Enninger 1980a, p. 41). ${ }^{4}$

The beard and kapp / bonnet represent signeme paradigms, G\&GP options for a single functional slot. Enninger further tests his paradigm with garment configurations (simultaneous signemes) using the male torso as a case. He identifies three possible layers: lower (the shirt), middle (the vest), and upper (the jacket or coat) as well as the meaningful signemes - notice the detail of each article that is itself simplified-filling these slots:

Lower: shirt with a stand up collar, buttons, and solid material, either white [1] or coolcolored/tinted [2]

Middle: vest with hooks \& eyes and no outside pockets, either navy blue [3] or dark grey-black [4] Upper: jacket with a stand up collar and hooks \& eyes or snaps (no buttons), and either navy blue [5] or dark grey-black [6]; solid-dark color insulated jacket, altered if store-bought [7]; frock coat navy blue [8] or dark grey / grey-black [9] frock coat).

Enninger's table of combinations is reconstructed in Figure 5. One cannot help but be struck by Enninger's careful attention to the multitude of configurations and their meaning; these are rich data! Males select a given configuration, the attributes of a role, in anticipation of a social event-or even multiple social events, as the upper layer is removable. Configurations eight through 19 are the most complex, representing situations where role-taking is prescribed, where role-making is negatively sanctioned, and where little verbal transaction is necessary to determine roles. Such configurations are characteristic of socially critical, institutionalized events. Alternatively, configurations one through three consist of but a color shirt. Such configurations are produced in anticipation of diffuse interactions, where roles are partially made, often through verbal discourse; such is necessary and not negatively sanctioned. We could say such interactions are informal because the clothing permits the wearer to step into multiple roles and multiple social events with but a single configuration-albeit never allowing the Amishman to "pass" as anything other than Amish, thus still anchored as community-specific.

Characteristics of role attributes attest to the relative importance of a given role to the community. Obligatory roles_-those that must be performed-hold a central place and consequently have more elaborate role attributes. ${ }^{5}$ Optional roles hold low social importance and have "minimal or absent bundles of peripheral [...] attributes” (Enninger 1984a, p. 80). 


\begin{tabular}{|c|c|c|c|c|c|c|}
\hline \multirow{2}{*}{\multicolumn{2}{|c|}{ 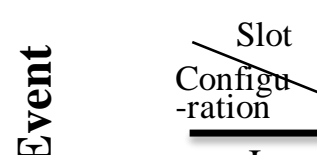 }} & \multirow{2}{*}{$\begin{array}{c}\text { Lower } \\
\text { level }\end{array}$} & \multirow{2}{*}{$\begin{array}{c}\text { Middle } \\
\text { level }\end{array}$} & \multirow{2}{*}{$\begin{array}{l}\text { Upper } \\
\text { level }\end{array}$} & \multicolumn{2}{|c|}{ Social Constraint } \\
\hline & & & & & Bio-social status & Social Event \\
\hline & $\mathrm{I}$ & 1 & - & $\begin{array}{l}\varnothing \\
5 \\
7 \\
\end{array}$ & Male over $1 \frac{1 / 2}{2}$ years & Everyday \\
\hline S & II & 2 & - & $\stackrel{5}{\varnothing}$ & Male from $1 \frac{1 / 2}{2}$ to 12 & Travel, shopping \\
\hline ซ & III & 2 & $\stackrel{3}{\varnothing}$ & $\stackrel{5}{\varnothing}$ & $\begin{array}{l}\text { Male from } 12 \text { to } \\
\text { baptism }\end{array}$ & Travel, shopping \\
\hline$\underline{\sim}$ & IV & 2 & $\stackrel{3}{\varnothing}$ & $\begin{array}{l}5 \\
8 \\
\varnothing\end{array}$ & $\begin{array}{l}\text { Male from baptism } \\
\text { to } 35\end{array}$ & Travel, shopping \\
\hline ע & $\mathrm{V}$ & 2 & $\stackrel{4}{\varnothing}$ & $\begin{array}{l}6 \\
9 \\
\varnothing\end{array}$ & Male over 35 & Travel, shopping \\
\hline ț & VI & 2 & - & $\stackrel{5}{\varnothing}$ & Male from $1 \frac{1 / 2}{2}$ to 12 & Visiting \\
\hline 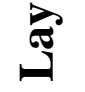 & VII & 2 & $\stackrel{3}{\varnothing}$ & $\stackrel{5}{\varnothing}$ & $\begin{array}{l}\text { Male between } 12 \text { and } \\
\text { baptism }\end{array}$ & Visiting \\
\hline Eِ & VIII & 2 & $\stackrel{3}{\emptyset}$ & $\stackrel{8}{\varnothing}$ & $\begin{array}{l}\text { Male between } 12 \text { and } \\
\text { baptism except } \\
\text { ministers }\end{array}$ & Visiting \\
\hline$\Xi$ & IX & 2 & $\stackrel{4}{\varnothing}$ & $\stackrel{9}{\varnothing}$ & $\begin{array}{l}\text { Male over } 35 \text { except } \\
\text { ministers }\end{array}$ & Visiting \\
\hline • & $X$ & 2 & 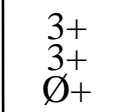 & $\begin{array}{l}8 \\
\varnothing \\
8\end{array}$ & Minister under 35 & Visiting \\
\hline مِ & XI & 2 & $\begin{array}{l}4+ \\
4+ \\
\emptyset+\end{array}$ & $\begin{array}{l}9 \\
\varnothing \\
9 \\
\end{array}$ & Minister over 35 & Visiting \\
\hline & XII & 2 & - & 5 & Male $1 \frac{1}{2}$ to 12 & On way to service \\
\hline $\bar{y}^{2}$ & XIII & 2 & 3 & 5 & Male 12 to baptism & On way to service \\
\hline 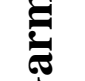 & XIV & 2 & 3 & 8 & $\begin{array}{l}\text { Male from baptism } \\
\text { to } 35\end{array}$ & On way to service \\
\hline & $\mathrm{XV}$ & 2 & 4 & 9 & Male over 35 & On way to service \\
\hline ע] & XVI & 2 & - & 5 & Male from $1 \frac{1}{2}$ to 12 & Church service \\
\hline$\ddot{g}$ & XVII & 2 & $\begin{array}{l}3+ \\
3+ \\
\dddot{\emptyset}+\end{array}$ & $\begin{array}{l}5 \\
\stackrel{\varnothing}{5} \\
5\end{array}$ & $\begin{array}{l}\text { Male from } 12 \text { to } \\
\text { baptism }\end{array}$ & Church service \\
\hline 坣 & XVIII & 2 & $\begin{array}{l}3+ \\
3+ \\
\stackrel{0}{\emptyset}\end{array}$ & $\begin{array}{l}8 \\
\varnothing \\
8\end{array}$ & $\begin{array}{l}\text { Male from baptism } \\
\text { to } 35 \text { except } \\
\text { ministers }\end{array}$ & Church service \\
\hline$\ddot{\theta}$ & XIX & 2 & $\begin{array}{l}4+ \\
4+ \\
\emptyset+\end{array}$ & $\begin{array}{l}9 \\
\emptyset \\
4\end{array}$ & $\begin{array}{l}\text { Male over } 35 \text { except } \\
\text { ministers }\end{array}$ & Church service \\
\hline 苋 & $\mathrm{XX}$ & 2 & $\begin{array}{l}3+ \\
\emptyset+\end{array}$ & $\begin{array}{l}8 \\
8\end{array}$ & Minister under 35 & Church service \\
\hline & XXI & 2 & $\stackrel{4+}{\emptyset}+$ & $\begin{array}{l}9 \\
9\end{array}$ & Minister over 35 & Church service \\
\hline
\end{tabular}


Role attributes are not mere mathematical formulas with fixed outputs. Enninger permits room for the interaction between social expectations and agency by distinguishing among actors who are merely fulfilling vs. over-fulfilling vs. not fulfilling a given role attribute, for example, beard length or amount of the ear the kapp covers. Actors who are not fulfilling may be subject to sanctions, although Enninger also observed some sanctions circumvented when an Amishman explains away deviance, such as the beard will not grow further or-jokingly — that it is shrinking. The probable effect of not fulfilling a role attribute is to suspend the group's sense of we-ness, as alter asserts an individual identity against the group expectations of role attributes, or rather, asserts an identity to which he is not entitled, thereby challenging the role system, not to mention the central community values that have produced the role system (Enninger 1980a; 1982). Consequently, we can understand the disruptiveness of what outsiders may see as slight changes in dress as deviance in dress, as a social action is inseparable from the whole string of superstructural steps that produce the role system and its attributes.

(b) Role attribute explanations: Beyond grooming and garment patterns

While Enninger conducts the bulk of his role attribute theorizing with G\&GPs, he later addresses other role attributes. Tapping into Stephen Scott's encyclopedic knowledge of Amish settlement and affiliation practices, Enninger argues that Amish and Old Order Mennonite buggy styles represent information about relative closeness of affiliations (that is, buggies as attributes of whole systems of roles and roles within the systems), and consequently whether an interaction should be opened between interactants (Enninger 1984d; Enninger, Hostetler, Raith, and Wandt 1989; Enninger and Scott 1985). Additional role attributes and settlement-specific role systems are conceivably stored not only in nuances of buggy styles (Scott 1981[1998]), but other Amish symbol systems that Scott later meticulously cataloged yet lacked a theoretical framework from which to derive meaning, including technology use / non-use (Scott and Pellman 1990[1999], pp. 9,59,112), architectural styles (Scott 1992[2001]), and ritual performances (Scott 1988).

Enninger insinuates that many more are the nonverbal role attributes beyond G\&GPs and buggy styles, but these explanations suffice to explain his role theory contributions.

In sum, Enninger has taken his original question of "Who uses what language when?" and reframes it with reference to the Amish sign system: "Who displays what artifacts on which occasion?” (Enninger 1984d). Until now, we have been analyzing people’s expectations of role attributes to be displayed, the shared knowledge that premises and prefaces social action. This is not the social action itself, the actual "utterance" of a symbol at the onset of an interaction and the ensuing interaction, to which we now turn.

Role Identification and Interaction (Level “ $g$ ” in Figure 2)

As contact ensues, people demonstrate role-characteristic behaviors to be identified with that role. Unless the relevant role attribute expectations are met, the behavior does not count as the performance of the role. Role behavior must conform to expectations of role attributes, so 
that interactants can identify the role being performed. Some role enactment is created at the event, including spoken language, posture, and qualifications / skills. Others are part of one's being, including gender, age, and marital status. The G\&GPs constitute an in-between category. They are configured in private in anticipation of a social event and are "uttered" to others only when in their presence, just as a sentence is mentally constructed prior to being spoken. G\&GPs are "irreparable" once at the social event, meaning that unlike language, they cannot respond to negative sanctions or miscommunication. Consequently, the information for performing a clear utterance is widely known so a faux pas is much less likely visually than verbally, as speech can be repaired at the event. G\&GPs can only be repaired in private in anticipation of the next social event (Enninger 1980a, pp. 48-49; Enninger and Wandt 1982, p. 127).

Upon visual identification of co-religionists—-most immediately through dress—a shared sense of “our people's” orientations (mental, emotional, and normative) is established, which activates empathy, affection, and solidarity while also creating a sense of "our" separation from the gaily dressed. This process begins among the youngest children, who learn to identify and trust those enacting community-based roles, even strangers (Enninger 1980a). ${ }^{6}$

The interaction's rules and structure are inferred from mutual identification and include at minimum the following.

\section{(a) Role privileges}

First, with the identification of roles, role privileges appropriate to a role's status are distributed. Privilege distribution may be symmetrical or asymmetrical. Symmetrical privileges exist when role attributes match. Given the conversational ease when symmetry exists, Amish often arrange themselves in peer and gender groups. Such role-mirrored situations guarantee shared topics of interest due to shared experiences. Asymmetrical situations occur most often during central social events, such as the church service, where role privileges are based on gender, age, and ordination status. For example, the ordained have speaking privileges, baptized men may lead singing, and adults are seated first at both the service and meal (Enninger 1980a, pp. 59-60; 1982, pp. 116-17). Asymmetrical situations often require that the higher status individual grants discursive privileges to lower status individuals, as with the teacher-student relationship or the Vorsanger requesting a younger married man lead a song. Outside formal events, genders casually separate for conversation, as role privileges in vertical relationships within gender groups are more easily determined (Enninger et al. 1989).

(b) Speech rules and content

The conversation follows community-specific rules. Addressing one another often occurs with informal pronouns. This expresses the concept of church as intimate community. Also, certain topics are considered part of the community’s common knowledge, notably values, norms, and orientations, so are omitted from conversation, as their topicalization would be either redundant to lived practice or suspect, e.g. introducing subtle change. Furthermore, as with the 
optional interactional opening of silence, long pauses are tolerated. Silence is an invitation for equals to speak. If the opportunity is not taken, silence is preferred to insincere babbling that questions empathy. Much more information is transacted through silence, to the extent that even if an outsider happens to know PG, he may still not understand what is communicated with a pause (Enninger 1980a; Enninger 1985; Enninger, et al. 1989). In one piece about silence across cultures — with a section about the Amish—Enninger writes,

In another sixty minute conversation which developed in the course of what was intended as a Saturday afternoon visit to another OOA living about five miles away, we found no fewer than 85 between-turn silences of five seconds or more. Of these, 29 were longer than ten seconds, 16 were longer than 15 seconds, eleven were longer than 20 seconds, namely 55, 38, 36, 35, 29, 27, 26, 24, and twice 22 seconds. (Enninger 1991, p. 17)

Meticulously documented field research, to be sure!

Furthermore, phatic speech - that is, speech for social / emotional purposes rather than informative - is omitted, as it is deemed redundant to information transacted nonverbally, such as an intended role. Among phatic speech eliminated are conversational openings; Amish either move straight into the subject at hand or open with a pause that, in duration, would make most non-Amish uncomfortable. Any conversational openings offered are non-emotional and matterof-fact. For example, greetings, if offered, are non-propositional (“Hello,” or “Good morning”) and emotionally neutral ("There you are, then" or "You haven't been here for some time"), not expressive, which risk insincerity ("I missed you” or "It's good to see you again”). Through the conversation, other phatic speech is eliminated, including endearment terms, discourse lubricants, cajolers (“right?” or “you see”), and receipts (“oh” or “m-hm”). Such speech is considered insincere due to its redundancy of what is already a given by merit of community membership - affection, empathy, equality, and attentiveness. These values stem from the "weness" that is continually affirmed throughout the interaction with the ever-present G\&GPs (Enninger 1979b, p. 474; 1980a, pp. 53-55; Enninger, et al. 1989, p. 156).

(c) Language choice and the diglossia situation

Finally, and receiving the most attention, is that role identification determines conversational language. In research on roles and language choice, Enninger is returning to an initial question as a sociolinguistic: for the three language varieties available (diglossia), in what situations do they use which language? Enninger's extensive theorizing channels back to this question, and it evidences his willingness to find meaningful answers, even if it means taking the long route.

The linguistically able Amishman has three languages at his disposal: Pennsylvania German / Dutch (PG), American English (AE), and Amish High German (AHG). In several places and at varying levels of complexity, Enninger diagrams the relationship between roles and languages (Enninger 1986a, p. 202; Enninger and Wandt 1979, p. 64; 1982, p. 135; 1984, p. 43). 
Criteria for language selection include primary vs. secondary roles; written vs. oral correspondence; a personal vs. transactional communication; and interaction within other Amish vs. plain Anabaptists vs. the mainstream. Examples of roles that are Amish, transactional, oral, and ritualistic include the preacher (if the role is speaking) or Täufer and Vorsinger (if the role is reciting). Roles that are intra-plain Anabaptist, oral, and transactional are conducted in English (e.g. customer or co-worker), whereas when the criteria switches to personal instead of transactional, the roles implied are family members who joined different affiliations. The choice of language is functional in that it signals a role.

PG is the language attribute of most roles, notably, those activated when intra-community interaction occurs. In the broader galaxy of plain Anabaptist groups, PG may also be used after initial English probing. PG thus symbolizes collective social identity, a shared language representing the role system of "our" world against "theirs.” PG is even chosen when Amish converse with each other in front of someone who does not understand PG, not to be rude, but out of role relationship considerations (Enninger and Raith 1988; Enninger and Wandt 1979). Because PG is group-specific and a language of intimacy, it is unstandardized, a vernacular.

English is an impersonal language, primarily for use with outsiders (Enninger and Raith 1988). English is a standardized language, and hence, lending itself well to the formal language of instruction in school, whereas PG is only learned informally. Both Frey and popular works (e.g. those referring to "Dutchified English") posit that the English of the Amish experiences interference from PG, "built on a framework of Pennsylvania Dutch phonemic patterns and interjected continually with whole or part loan-translations” (Frey 1945, p. 86). Enninger hypothesizes this supposition as false, presumably because English is a role-specific attribute that is an out-group variety and consequently demanding clarity. One also senses that Enninger wants to push back against the "dumb Dutch" and "verhoodled English” stereotype of popular pamphlets. This rare defender-posture of Enninger seems furthermore validated in his use of an in-passing quote from John Hostetler-self-appointed defender of an incorruptible Amish image-to serve as a counter-thesis to the popular "verhoodled English" stereotype.

Enninger uses three strategies to suggest the "verhoodled" thesis is false, analyzing phonology (sound), morpho-syntax (various usages), and lexicon (words). First, he records nine “(ex) Amish” and nine local non-Amish reciting a standard text, and then asks local non-Amish to identify which recordings were Amish. By and large, they failed. A few consistent interferences are documented, but Enninger concludes thus: "When one compares the interference potential with the actual interferences, the latter appear almost negligible” (Enninger 1987a, p. 563). Second, Enninger and associates analyzed 21 hours of taped conversation, 60 letters, and 200 Budget / Botschaft columns. He concludes that the Amish have a 99\% accuracy rate in schoolbook-sanctioned English. Finally, Enninger suggests inductively that the examples of "verhoodled English" are from Amish speaking to Amish, and that such a situation is implausible given PG, not English, is used in these situations as an outcome of internal role selection (Enninger 1984c; 1987a; Enninger and Essen-Delaware Amish Project Team 1985). 
Despite these conclusions, Enninger fears that false stereotypes of the Amish's English has moved permanently from popular tourist brochures to respectable school textbooks and academic sources (Enninger 1987a, pp. 573-75). He feels he has nevertheless demonstrated that the "verhoodled English" thesis would be sufficiently dysfunctional to Amish roles requiring English that it would be near non-existent. One must wonder if, in his zeal to debunk an embarrassing stereotype, he overstated his findings, despite his general cautiousness to not. What sense would he make, for example, of Holmes County, $\mathrm{OH}$, where there is at least initial evidence to suggest much more interference for an Amish-Mennonite sample (Downing 2015)?

Amish High German is associated with the fewest roles. Its primary use is with roles in ceremonial situations (Enninger and Raith 1988), this due entirely to High German being the language of central religious texts - the Luther Bible, Ausbund, Dortrecht Confession, writings of Menno Simons, and others. A non-productive, classic language, AHG is generally unavailable for new, ad hoc coding of speech. Its phraseology is basically fixed in whatever the German texts present. The Fraktur / Gothic script-used commonly in Germany until the Nazis banned it in 1941 - further reinforces the texts' classic, traditional nature against modern fonts, in which time-specific periodicals like The Budget and Family Life are set.

The functionality of language choice to role enactment requires language skills. With three languages and at least six language skills to accompany each (Figure 6, rows), the structural demands are high.

Because AHG is non-productive and an attribute of the fewest roles, it has undergone economization. For example, its rules of use (speaking, spelling, etc.) have become destandardized and variable, collapsing many distinctive rules into AE and PG rules. Yet, AHG has high prestige because of its association with religious texts, so it is not easily dropped. Nevertheless, it is the most costly of the three languages to learn. AHG-associated roles are rarely enacted, and its other uses (e.g. letter writing) are optional roles. Because AHG provides access to religious texts, it is deliberately taught in the upper grades in school, but primarily to read, not write or speak, so the skill-set demanded is low and as attainable as possible. The Amish, as a community-oriented social group, find important religious messages constructed in times past, which continue solidifying the group with a core, unchanging value system (Enninger 1984b; 1986a; 1986b).

This, Enninger says, is economical management of language internalization (Figure 2, bottom). Amish recognize the functionality of language choice yet realize that everyone learning to read, write, speak, etc. three languages is demanding. Consequently, Amish juggle language education judiciously, concentrating on language skills covering common roles. They also permit variability in language acquisition. Enninger catalogs the skill levels of three types (Figure 6, columns): the lowest skill set (I) characteristic of children; the highest (III) characteristic of the ordained and elderly; and the intermediate (II) characteristic of adolescents and adult laity. 


\section{Figure 6: Three Examples of Language Skill Sets for Common Amish Roles}

\begin{tabular}{|l|l|l|c|}
\hline \multicolumn{1}{|c|}{ Skeaker Type } & \multicolumn{1}{|c|}{$\mathrm{I}$} & $\mathrm{II}$ & $\mathrm{III}$ \\
\hline Listening Comprehension & $\mathrm{AHG}+\mathrm{AE}+\mathrm{PG}$ & $\mathrm{AE}+\mathrm{PG}+(\mathrm{AHG})$ & $\mathrm{PG}$ \\
Reading Comprehension & $\mathrm{AHG}+\mathrm{AE}+\mathrm{PG}$ & $\mathrm{AE}+\mathrm{PG}+(\mathrm{AHG})$ & $\mathrm{PG}$ \\
Written Text Production & $\mathrm{AE}(\mathrm{PG})+(\mathrm{AHG})$ & $\mathrm{AE}+(\mathrm{PG})$ & \\
Written text Reproduction & $\mathrm{AE}, \mathrm{AHG}, \mathrm{PG}$ & $\mathrm{AE}+(\mathrm{AHG})+(\mathrm{PG})$ & \\
Oral Text Production & $\mathrm{AE}+\mathrm{PG}+(\mathrm{AHG})$ & $\mathrm{AE}+\mathrm{PG}$ & $\mathrm{PG}$ \\
Oral Text Reproduction & $\mathrm{AE}+\mathrm{PG}+\mathrm{AHG}$ & $\mathrm{AE}+\mathrm{PG}+\mathrm{AHG}$ & $\mathrm{PG}$ \\
(reciting, singing) & & & \\
\hline
\end{tabular}

To summarize language use, PG and AHG are attributes of primary roles, as the exchange of an in-group language signifies “we-ness.” AHG, because of its limited productivity in coding new information, is relegated to central roles during ceremonial events. Enninger argues that, more than any other force, the use of PG and AHG as attributes of community roles is what preserves these minority languages in an English society (Enninger 1988c). Roles requiring AE are secondary and transactional (with the exception of student-teacher when class is in session). Frey’s (1945) “occasions” (let alone locations) for language selection is an unreliable predictor of language choice. Rather, roles taken - which nevertheless can be social event-specific (next section)_-determine language choice (Enninger and Wandt 1979).

\section{Self-Reproducing Cycles: Interactions Reinforce the Superstructure-Level " $h$ ” in Figure 2}

The next level of social action, “Effect on 'Uberbau' (Superstructure)” consists of selfreproducing cycles. As actors regularly conform to role expectations and demonstrate role attributes through many micro-interactions, the superstructure is stabilized. The values and norms of the superstructure are given constant reinforcement, and, consequently, everyday social action assumes religious significance. This notion is reminiscent of Cronk's (1977) assertion that religious ritual is not limited to sacred events but penetrates all of life, "social rituals” (e.g. visiting, dress, family relations, and work). And if plain Anabaptism is more comparable to the monasticism of Catholicism than the individuation of Protestantism (Gilland 2017), then Enninger's assertion has broad—if not relatively undertheorized—support.

(a) Systemic reinforcement versus Amish “modernism”

In a paper testing the tenets of modernism to the Amish situation-likely written for the Young Center's inaugural conference “Coping with Modernity” in 1987_ Enninger finds that 
the Amish diverge from modernism in five ways. All address the Amish community as a reality lived in day-to-day interactions that in turn reinforce the values and norms of the superstructure.

The first tenet of modernism is abstraction and abstract social structures, which results partially from the proliferation of communication technologies and the reach of bureaucracies into everyday life. For the Amish, their social order is reinforced through ongoing interactions of the immediate community, where symbols are both collectivized and localized, a contrast to modernism's abstract, fluid, and diffuse symbology.

Second, while modernism is future-oriented — driven by a progress narrative- the Amish orientation is to the crucial religious events of the past and the unchanging moral demands arising from these events. Constant interaction reinforces this orientation, as it reminds interactants of what the community requires of members and also serves to monitor and stymie attempts to introduce the progress-narrative.

Third, modernism advances individuation, whereas Amish are embedded in overlapping and nested social networks, which all have their levels of sign systems. Frequent interactional enactment of the role system reinforces the norms that give shape to the role system.

Fourth, modernism posits liberation as a chief goal, liberation from structures of the past, replacing routinization with options. On this point, Enninger casts Olshan's (1981; 1984) argument - that Amish are modern vis-à-vis exercise of choice-into question by suggesting a paradox: that while Amish members chose to join the Reformation movement in the 1500s, then chose in the mid-1800s to remain strict, and that while individual Amish may join to be part of the community or to leave, ultimately, the Amish structure limits individual choices, the left column of Figure 2. Limitation of choice in daily life is what allows Enninger's theory to work: consistent expectations of roles arise only from the minimization of individual choice. People conform rather than create roles in interactions central to the community.

Fifth, modernism propels secularization, the decline of religiosity as an important variable in public life. Amish think of themselves as first a religious group, then second a social group. Their role system is communicated through symbols considered primarily religious, secondarily social. This order creates a by-design defense against secularization, that without the religious (value) community, no social community would exist (Enninger 1988a; 1988b).

In these five ways, Enninger argues that the Amish have coped with modernity without capitulating to its tenets, that frequent interaction (symbolic enactment of the role system) reinforces their non-modern orientation in five measurable ways. Heretofore, Enninger's critiques of a relatively unknown scholar, Frey, and of the "Ferhoodled English" stereotype may seem remote. Now, Enninger hints at a critique of Olshan's (1981) contention that Amish are modern if measured by choice, as for Enninger, "choice" is hardly so simple a variable set within his nuanced theory described in this article. 
(b) Systemic reinforcement with speech rules

An illustrative case of the feedback loop between the enacted role system and the superstructure is the development of rules of speech, rules being value-driven norms and speech being an interactional mode that realizes roles. Through repeated interactions, the whole way speech is constructed conforms to the superstructure values. Enninger identifies four categories of speech constraints: quantity, quality, relevance, and manner. Amish limit quantity on the basis of religious principle ("let your yea be yea and your nay, nay") and also in limiting redundant information communicated through nonverbal channels. They control quality in omitting lies and irony; they admit “I don't know” or uncertainty quickly on something they may even be fairly certain about. Relevant topics address what interests, impacts, and concerns the community; alternative worlds, arguments over Scripture (which is non-negotiable), unscrupulous dealings, and rowdyism among the young are not topicalized publically, except when necessary. In like manner, Amish seldom use embellished rhetoric or lofty tones, as such speech is seen as inauthentic and as appealing to emotion, feeding structural instability (Enninger et al. 1989).

\section{(c) Systemic reinforcement and gradual social change}

The cycle of interaction and superstructure need not necessarily result in a fixed system; the system may evolve, albeit slowly. Enninger surmises that the core value of "our people” and the tension with "their world" could inform a language shift. Though he argues that change in PG toward English was a sign of PG's viability, should English eventually overtake PG in its entirety, the Amish version of English would still be distinct from American English in the way it is spoken, not just in accent, but in construction and rules. In this case, “Amish English” would be considered "our language.” Enninger observed that the Amish in Honduras during the 1970s (Anderson and Anderson 2016) maintained English even though it served no out-group function, yet, it became "our language” in a non-English context. Similarly, Amish have taken many nonverbal symbols and made them symbolic of "our” world, including buggies, windmills, and horse-drawn implements. Indeed, Amish find it worth the cost and inconvenience to maintain whole systems of verbal and non-verbal symbols that define "our world" versus "their world," whatever those symbols may be, so long as they are consistent with the superstructure's value system. The benefits include a communication barrier, an interaction barrier, a barrier to outsiders joining (who are not socialized Amish since childhood), and facilitation of endogamy.

As their adherence to inefficient means of transportation (buggies), their preference for an earlier generation of farm-implements and technological equipment, their maintenance of an impractical folk-costume, their reticent use of such convenient things as the telephone, the complete rejection of radio and TV as well as their cooking from scratch (rather than serving store-made meals) show, the [Amish] are willing to sacrifice a great deal for the maintenance of the distinctness of their socioreligious ethnos. (Enninger 1986a, pp. 2111-12)

And as the world changes its symbols, the Amish change theirs, albeit slowly and only through many repeated interactions where consensus over the change is forged. Their socio-religious 
identity, which happens to have a Germanic past and expression, especially in language and dress, must be maintained for their values to be protected.

\section{Social Contexts (Level “i” in Figure 2)}

Role-based enactments and interactions produce the social event, notably the events central to the group's functioning. Roles are very often event-specific, and given the incredible density of social relations, different social events may occur with the same people in the same space, for example, the house as site of church service, wedding, funeral, work, visitation, and family privacy - this contrasted to the fragmentation of modern life where church services are in sanctuaries, work is at the office or store, visitation is over a meal in a restaurant, and family privacy in the home competes with individual privacy. Consequently, location in and of itself is an insignificant generator of the social event. For the Amish, role-taking - enacted through the verbal and non-verbal cues discussed above-defines the social event, and consequently the roles available and the responsibilities and privileges distributed to individuals. Enninger's definition of the Amish church service - as the community's central social event-fits other social events to a degree as well: “an institutionalized, stable, culture specific (emic) face-to-face interaction pattern of interrelated verbal and nonverbal components” that is rule-governed (e.g. roles, spacing, and message forms), derives stability from sacred tradition, and confirms the status quo (Enninger and Raith 1982).

Enninger distinguishes between diffuse social events that arise from role-making and central (i.e. of great importance to the community) social events that demand role-taking. While central social events have high rule governance and fixed expectations, diffuse social events have fewer "must" expectations and more may-or-may-not expectations. Central social events are typically the consequence of roles whose attributers are quickly and easily identified due to clear expectations of role performance (Enninger 1980a). Roles signaled with elaborate ("peripheral”) attributes and high social control over attributes signal central social events. Roles with few attributes and low social control signal diffuse social events. Grooming and garment patterns in such situations consist of the simplest outfits (e.g. man's colored shirt and trousers), which are assembled at the beginning of the day and perform numerous diffuse roles, albeit still identifying the wearer with the religious community. Given the reduced symbolic currency of basic G\&GPs, their accompanying social events are also of reduced significance to the community. The mainstream parallel is the ubiquitous T-shirt-and-jeans outfit, which is even more "casual” inasmuch as it also signals no allegiance to a particular group, let alone a given social event. Elaborate G\&GPs particular to a certain social event signify the importance of that event and the role performed (Enninger 1980a). While Amish have the ability to participate in many diffuse social events, the Ordnung still defines negatively sanctioned interactional realms, especially through requiring a costume that misaligns the wearer with an incongruent social event, such as a tavern or inner city street on Saturday night (Enninger and Wandt 1982). 
Diffuse social events are of limited depth due to their variability. Enninger spends most effort recounting the order of central social events, namely the church service- - his single largest exposition, contained in a small book — and the Amish school. While many scholars of the Amish both before and after Enninger have accounted these two social environments-indeed, have written whole books filled with nuanced distinctions and descriptions - none have made more than superficial theoretical sense of these events. The following descriptions only touch on select elements of Enninger's theorizing, only what pertains to roles and the social event.

Of the church service, the transition from an everyday / family social event to the sacred religious service occurs just prior to the ritual's performance. Family roles such as father / mother and brother / sister are disassembled upon arrival and members enact several mostly silent rituals, such as the handshake greeting, separate entry of the genders, age-graded entry, and the late arrival of youth that signal acceptance of community-significant roles and role status, namely, ordained / laity, non- / member, male / female, and age group. The ordained have the most status, and as such have the greatest role constraints, to the end of subjecting to the community the individuality of actors filling the role. By selecting who will preach only that morning, choosing ministers from an untrained laity, and subjecting sermon oration to a rhythmic sing-song beat and tune, little room remains for the preacher to make the role into a position of charisma or philosophizing, such as preparing a well-crafted talk or using dramatic pauses / emotional effects. Instead, preachers quote Bible passages and, assuming a shared set of values and knowledge, merely admonish the hearers to do what they already know is right. Whereas many religions (and organizations) seek a man who can give definition to a leadership role, the leadership role is pre-defined and shapes the man who fills it; he is an agent of the institution. At the service's conclusion, groups depart as peers, and everyday roles are gradually reassembled as families leave. Overall, the service is characterized in ritual, speech, and G\&GPs as having many peripheral role attributes that may serve no rational function other than "tradition," which lends significance and authority to the event (Enninger and Raith 1981; 1982).

The school, as with other central social domains, consists of purposeful social action organized according to community values, and the roles and signals particular to this event represent such organization. G\&GPs signal both the oneness of the in-group and distinctions, in this case between teacher and scholars. The teacher exhibits appearance items signaling baptism status, and, thereby, she (1) signals power to mediate interactional privileges, and (2) serves as an example of community norms to be internalized. Of the first, the demand for speech is high due to several grades sharing one teacher, and its high demand means it must be managed silently. The teacher moderates speech through visual cues first—written assignments on the board or gesticulation to scholars across the room-and oral acknowledgement second, often after a moment of silence accepted by the scholar. This management of communication symbolizes power differences that stand in lieu of formal address, such as using Ihr/Dir instead of du or in using name titles ("Miss Miller"). The emphasis on equality within the brotherhood means the community is on a first-name basis, even in school, although the tendency in school is to omit 
name-usage on most occasions. Scholar roles are formal when class is in session, signified by their use of English and High German (in German lessons), whereas roles are relaxed to a degree during recess and lunch, signaled by the use of PG (Enninger 1987b). The social event school, a central Amish socialization context, exhibits such high continuity and stability that its forms are replicable to U.S. one-room schools of a century ago, with minimal innovation (Enninger 1999).

In sum, the combination of certain non-verbal and verbal role attributes and privileges creates social events, here illustrated through "church service” and "school.” Social events central to the community have greater expectations and demand role-taking, whereas diffuse social events permit role-making.

\section{The Periphery / The Social and Natural Environment (Right Column in Figure 2)}

Due to the relative homogeneity (e.g. genetic, occupational, hobby) and intense intragroup interaction (dense social networks), the level of agreement on roles is assumed high (vis-àvis structural functional role theory) and that interactions in the diffuse value sphere (e.g. with outsiders and other Amish and plain Anabaptist people, where norms and roles are ambiguous) are few. Yet, the diffuse - or peripheral - is part of the overall superstructure. Enninger explains the peripheral in less detail, but it is a critical site for externally-induced social change, in the spirit of Hurst and McConnell’s (2010, pp. 20-25) “border work” on the cultural margins.

While central values and norms define the community, peripheral values result in vague norms for interactions beyond the community, including interactions with non-Amish and the broader network of plain people. For peripheral areas not essential to group functionality, interpretive practices result with no sanctions given for of-the-moment rules internalized. While roles and role norms at the core of Amish society are fixed, peripheral roles and norms are open to individual interpretation and many alternatives_role-making instead of role-taking. With role-making, role expectations must be negotiated. It is here that the production of roles and role expectations feeds back into the superstructure's system of roles, and that as once-temporal, ofthe-moment roles become repeated and fixed at the periphery, they can gradually move into the core role system, which then may or may not be consistent with the core values and norms (Enninger and Wandt 1979). This is a situation for change. However, given the extent to which Amish bring many potentially peripheral situations into the fixed core, change is relatively slow.

Perhaps most disappointing in all of Enninger's work is how open-ended he has left this less peripheral realm of the superstructure and of social action. We are left guessing at the right column of his theory diagram (Figure 2). Fortunately, he does not leave us thinking that he believes social change is but the product of gradual systemic adaptation; he also grants actors agency on the margins to instigate change. For example, consider this excerpt:

The most important factor that limits appearance-based role-taking are appearance utterances that are not in accordance with the status and event constraints conventionalized for the members of the community; this is the case when an interactant displays appearance behaviour that is not in line with 
his status or/and with the event to be staged. [...] If he is personally known, the identification-of process is transacted on the basis of that familiarity. Yet, at the same time, the identification-with is suspended because of the nonconformity that is symbolized. Through his non-conform appearance this person symbolizes that he is attempting to create a role for himself that he is not entitled to, whereby he challenges the role-system of the social structure. The sense he produces is "personal identity asserted against social identity”. In a society that puts all value on social rather than personal identity, it is plausible that such an attempt at nonverbal assertion of personal identity entails negative sanctions. (Enninger 1982, p. 172)

Any Amishman - or plain person for that matter-who has spent time suffering through church troubles knows this situation very, very well: an individual displays dress that negates the group's social identity, yet because the person is personally recognized and on that basis alone attains his roles and role privileges, the symbols are slightly marginalized as unnecessary and redundant, and this suggestion forces a situation where sanctions must either be reduced / overlooked or made at risk of causing wider unrest. Such are the seeds of gradual changes in dress - and technology, architecture, standards of living, buggy styles, and every other community-defined symbolic role attribute. A few researchers have documented such tensions among the Amish—Hamilton and Hawley's (1999) study of dress in Jamesport, MO, being a most insightful case-and it is unfortunate Enninger says no more on the matter.

Instead, the most attention he gives this peripheral realm is in documenting the ways that PG has become destabilized due to contact with the non-Amish, and this destabilization he argues is, ironically, functional to language stability. His argument goes like this. The Amish often complain that PG is becoming corrupted or diluted at the hands of AE. After all, because interaction with the outside is unavoidable, and because PG is an attribute of so many roles, outside demands are placed on PG. That said, the Amish do not switch to AE because it is not a language from which "we-ness” can be derived (Enninger and Wandt 1982, p. 136). However, should they simply freeze PG, the language would gradually become dysfunctional, as it would fail to capture the everyday life of a changing world. By destabilizing it, "Englishifying” it, PG can adapt and remain a viable, useful language. Enninger even goes as far as to suggest that, no matter the context or languages, the Amish value system will demand an intra-group language variety and an inter-group variety, as it helps enforce separation by defining different linguistic attributes of primary (internal) and secondary (outward) roles.

Thus, the most immediate threat to PG is not gradual language erosion or Englishifying but rather a theology of missions, which does not find value in linguistically defining the two social systems as separate, and which demands an in-group language that opens the door to members who have not been socialized into the system (have not internalized the concretization of norms) since infancy. Thus, the functional stability of PG as an attribute of internal roles will not change as long as the Ordnung remains fairly fixed and as long as society at large does not demand German be dropped. The whole process of changing PG relies on contact with the 
outside - in peripheral social realms with more role-making - while still grounding one's sense of identity in the group (Enninger 1979a; 1980b; 1986a; Enninger and Wandt 1982).

\section{Enninger's Alternative Model, Focusing on Social Change}

Figure 2 has received much mileage as a conceptual scheme around which Enninger's findings are organized. Worth presenting as well is Figure 7, which focuses on social change and language use, actually a reduced version of Figure 2. The social action system, representing the second tier of Figure 2, is influenced by both the superstructure (top blocks) and the contextual environments. The instrumental social action system (Weber) produces interactional needs met by role attributes, making language selection functional. Language choice requires language skills (Figure 6), which Enninger calls the structural verbal system.

\section{Figure 7: Amish Social System Theory, with a Social Change Focus}

Diagram 1: Heuristic model of relevant ecological factors

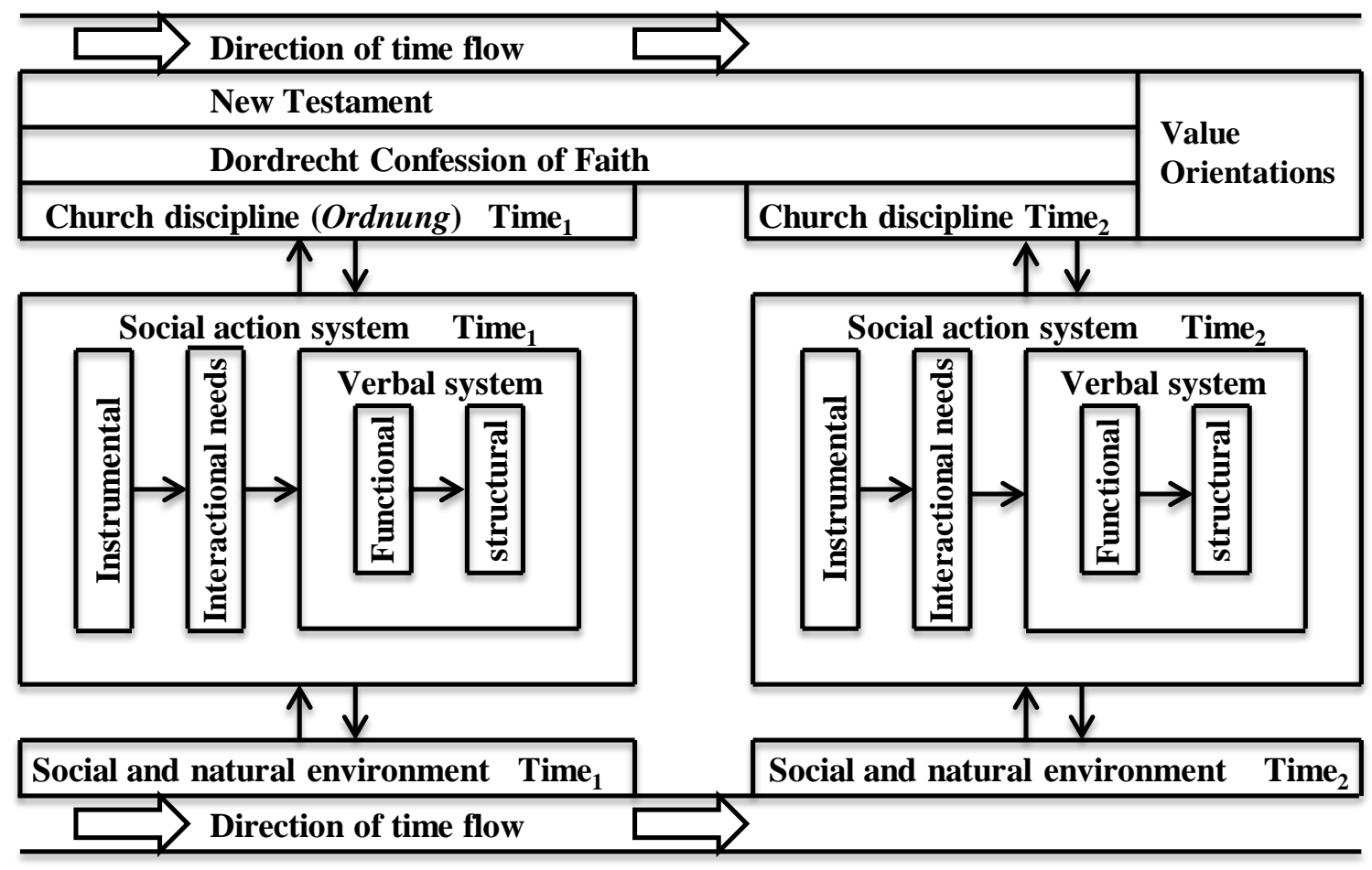

The diagram presents time one and time two. While some value systems are fixed across time, namely the New Testament and Dortrecht confession, the Ordnung and the social and natural environment change, and so does the Amish's interaction and symbols. The idea is captured in the now-familiar phrase "internal and external” sources of change. I find it fascinating that Enninger conceives of the Ordnung as unstable, prone to change, a source of internal change in itself, the Ordnung as a dialectic. Certainly, Ordnung has been conceptualized as an expression and source of diversity in our internal/external theorizing games, but I have 
never seen it as in itself an engine of change. It is a response, not a definer (e.g. technology taboos), of the Amish.

\section{Critical Reflection and a Call to Scholarship}

How has Enninger's oeuvre been so obviously omitted from our repertoire as scholars of the Amish? Worth noting are the pitfalls that nearly doomed Enninger's work to the abyss.

First, Enninger's writing style is difficult. Some sections take multiple reads, and his best articles are some of the longest. In an age when publications of all sorts, including scholarship, have proliferated, the hard pieces_-and especially the hard, unpopular pieces_-are easily cast aside. New scholars, even seasoned scholars, to the Amish find it easier to turn to, and keep turning to, scholarly reads that are the candy of scholarship, works that explain everything about the Amish in an easy formula, which are then packaged and promoted with pizzazz. The broccoli, quinoa, and goat milk of Amish scholarship — if you will_-may be hard to stomach at first, but is certainly the most nutritious. Consider: if the theory and methods are rich even if couched in challenging phraseology, is the neglect Enninger's problem or a case of scholarly lassitude, researchers not taking the time and mental energy to wade through waters with depth?

Second, the platforms Enninger used to publish are among the most obscure in Amish studies. For all of the odd, unusual journals and edited volumes that have consumed Amish research over the decades, Enninger's work takes the cake (or quinoa), and eats it too. Buried in festschrift, upstart journals edited by friends, and vaguely-defined edited volumes — and all of this straddling a mix of English- and German-language publications-Enninger seemed more concerned about publishing research than promoting it. Certainly that's a credit to his humility account—not to mention his priority of science over PR — but it was not ideal for offering future scholars his work.

The many pieces remind one of a single, shattered monograph, scattered fragments that require the researcher to put the pieces back together (the effort of this article). Not surprisingly, Enninger planned to tie the threads into a single book, at least he acknowledges as much at the conclusion of a 1986 conference paper (Enninger 1984c, p. 89). The monograph was to address familiar topics - language functionality and structure; nonverbal behaviors including grooming and garment patterns, buggy styles, and silence; and population / geography of the Dover settlement, as well as unfamiliar topics, including culinary practices and acts of signification and communication. Failure to produce a clearly articulated, organized, edited, and peer-reviewed English-language book consolidating his many peripatetic propositions is likely the one greatest incapacitation to greater acceptance of his ideas, a shortcoming this article has aimed to rectify.

Third, though Enninger was extremely productive given the limited scope of his research (the Dover, DE, Amish community and broader Amish texts), his writings fail to adequately develop predictions of social change, to account for religious conflicts and the surprising Amish diversity today. Hints are there, but not developments. This may very well have been the 
consequence of studying a community that has produced no other Amish branches, and even its non-Amish offshoots have been few. Or it may be his concerns with ethics and protecting the people who opened the door to him. But one has to wonder what he would have seen had his research been conducted in Holmes County, OH, or Adams County, IN.

Despite these shortcomings, they are hardly debilitating, not excuses for his neglect, and certainly not with this article paying overdue tribute. This summary of Enninger's work is a push on three fronts. First, Enninger's work has been woefully neglected, and it is time his meticulous labors and nuanced insights be referenced and cited in Amish studies research. Enninger's works may be difficult to attain, but with the library resources available at even modest institutions, all that should be needed is a bibliography_provided in this article, everything he published about the Amish in English — and a printer. So, ladies and gentlemen, students and professors, get your interlibrary loan staff working! (And if this article has been of use in your discovery of Enninger, reference it alongside but not in place of Enninger's masterpieces.)

Second, his theory needs to be tested and applied to current debates. The relationships between the ever-increasing baptism and retention rates could be read as an ever-strengthening of the system he articulated, as with continuity in the school system. Yet, Amish appear to interact at the periphery more than ever, a site of social change. Enninger does not see social changes as in themselves pernicious, but he would agree that social changes affecting the value foundations of the Amish would be damaging. This calls for research on groups that have assimilated, studying the way social changes first get their paws on core values and then how the instrumental action system begins unraveling in a reinforcing manner. For one, I have been weighing his articulation of Amish dress against the surprising presence of Amish fashion trends in progressive settlements and believe his work needs expanding along these lines to account for contradictions (or dysfunctions) in the symbol system to core values. ... And I could go on, naming the ways Enninger's theory provide an opening lens to explore current questions.

Third, I present Enninger as a model Amish scholar, perhaps the distinguished scholar if analyzing nothing but scholarship rigor. Even if his particular methods and theories are not a source of inspiration to scholars - those unimpressed by functionalism or symbolic analyses—his approach can be, raising the bar, the standards, on our research and publication quality.

\section{Endnotes}

${ }^{1}$ Contact information: Dr. Cory Anderson, Dept. of Society \& Env., Truman State University, 100 E. Normal Ave, Kirksville, MO 63501; 660-785-4032; dranderson@amishstudies.org

2 Enninger's (2002) annotated bibliography focused solely on language issues, of which there was no shortage by 2002. The book is generously lengthy despite its narrow focus, at 189 pages.

${ }^{3}$ I am not entirerly clear why Enninger has no "level a" in his superstructure; perhaps it is an omission or is simply the whole model itself. 
${ }^{4}$ To this point, Enninger's explanations have been compelling, although I feel here his interpretation is wrong. Nevertheless, another functionalist explanation may be convincing-e.g. bachelors have a distinct marriage signal because they are seen as having a choice in marriage whereas women are viewed as fated (not able to initiate a relationship), or that a woman is giving up the young-wife-will-have-a-big-family goal and is accepting her age-suggesting the strength of Enninger's classification hermeneutic, if not always a given interpretation.

${ }^{5}$ Enninger uses the term "peripheral” for "elaborate” for which he probably means "accoutrement” or "occasional, in excess."

${ }^{6}$ At a community yard sale in Holmes County, my wife and I passed two girls, roller blades in hand, zipping out of a basement "yard” sale. The homeowner was with a neighbor. On entering the basement, a four-year old boy was plopped in the middle of the floor, alone, shoes off and struggling to get them on. As I browsed the sale, the boy whimpered in Dutch and held out his quadruple knotted shoe. We picked away at it. With laces loosened and shoes returned, the boy slipped them on and ran off. My wife and I are Berea Amish-Mennonite, whose dress parallels New Order Amish dress. Though we do not know Dutch, the boy recognized the dress as of "our people,” establishing trust enough to ask for help in a language he had no reason to believe we did not know. This story illustrates Enninger's point, that symbolic patterns are ingrained from early childhood, mediating community trust.

${ }^{7}$ In my observation, and in the spirit of Enninger's theorizing of the superstructure, AHG's nonproductivity as a day-to-day language to a degree protects the core Amish value system, as new religious ideas cannot be linguistically coded out of a language arising from fixed religion texts. The pressures to change to English often come about as new theologies put sudden demands on religious language, to which AHG (or PG for that matter) cannot bend. Thus, when English is adopted, the changes in the superstructure and role system are sweeping, and hence why practically no Amish groups have switched religious services to English and have remained Amish beyond a generation.

\section{Appendix: Suggested Reading}

“Language Convergence in a Stable Triglossia Plus Trilingualism Situation.” [1979]

-The opening paper, as it were, to his theory and research questions

"Varieties, Variation, and Convergence in the Linguistic Repertoire of the Old Order Amish (OOA) in Kent County, Delaware,” with Joachim Raith. [1988]

-A summary of his language research

"The Semiotic Structure of Amish Folk Costume: Its Function in the Organization of Face-toFace Interaction.” [1982]

-The article that provides the greatest expansion of ideas about grooming and garment patterns 
“Kutschen Designs als Dinge und Zeichen,” with Stephen Scott. [1985] (in German)

-Enninger applies his ideas of grooming and garment patterns to buggy styles

“The Theme of Ethnicity in the Literature of the Old Order Amish.” [1986]

-Establishes core Amish values through an analysis of Amish literature

“On the Organization of Sign-Processes in an Old Order Amish (O.O.A.) Parochial School.” [1987]

-Explains the functionality of the Amish school and the way language and symbols are managed

"Coping with Modernity: Instrumentally and Symbolically, with a Glimpse at the Old Order Amish.”[1988]

-Employing Peter Berger's work, Enninger applies five tenets of modernism to the case of the Amish, pushing back against some of Olshan's assertions of Amish as modern

An Ethnography-of-Communication Approach to Ceremonial Situations. A Study on Communication in Institutionalized Social Contexts: The Old Order Amish Church Service, with Joachim Raith. [1982]

-The short book chronologically analyzes the Amish church service, explaining its functionality and role relations

"Participant Observation: Methodological, Psychological, and Ethical Problems Experienced in a Language Contact Study,” with Karl-Heinz Wandt. [1983]

-Enninger's reflection on methodology

"The Social Construction of Past, Present, and Future in the Written and Oral Texts of the Old Order Amish: An Ethno-Semiotic Approach to Social Belief.” [1988]

“Amish By-Names.” [1985].

—Going beyond past work on Amish nick-names, Enninger argues that they are not just an identifier but contain descriptive or evaluative information about others retrievable by insiders.

\section{Bibliography}

Adkins, Tabetha. 2011. "Researching the 'Un-Digital' Amish Community: Methodological and Ethical Reconsiderations for Human Subjects Research.” Community Literacy Journal 6(1):39-53. https://doi.org/10.1353/clj.2012.0014

Anderson, Cory, and Jennifer Anderson. 2016. "The Amish Settlement in Honduras, 19681978: A (Half) Failed Attempt to Develop an Amish Understanding of Mission.” Journal of Amish and Plain Anabaptist Studies 4(1):1-50.

Billig, Michael, and Elam Zook. 2017. “The Functionalist Problem in Kraybill’s Riddle of Amish Culture.” Journal of Amish and Plain Anabaptist Studies 5(1):82-95. https://doi.org/10.18061/1811/81074 
Braudel, Fernand. 1977. “Geschichte und Sozialwissenschaften: Die Longue Duree.” Pp. 47-85 in Bloch, Marcel/Braudel, Fernand/Febvre, Lucien ua: Schrift und Materie der Geschichte. Vorschläge zur Systematischen Aneignung Historischer Prozesse edited by Claudia Honneger. Frankfurt, Germany: Suhrkamp.

Burridge, Kate, and Werner Enninger. 1992. Diachronic Studies on the Languages of the Anabaptists. Bochum, Germany: Brockmeyer.

Cronk, Sandra. 1977. "Gelassenheit: The Rites of the Redemptive Process in Old Order Amish and Old Order Mennonite Communities.” Dissertation in the Divinity School. Chicago, IL: University of Chicago.

Donnermeyer, Joseph. 2017. “Of Shoulders and Shadows: Selected Amish Scholarship before 1963.” Journal of Amish and Plain Anabaptist Studies 5(2):162-95.

Dow, James. 1986. “Old Order Amish Preaching Style: Ring Construction, Structural Symmetry, and Nonverbal Communication.” Pp. 18-36 in Internal and External Perspectives on Amish and Mennonite Life 2, edited by Werner Enninger, Joachim Raith, and Karl-Heinz Wandt. Essen, West Germany: Unipress.

-. 1988. "Toward an Understanding of Some Subtle Stresses on Language Maintenance among the Old Order Amish in Iowa." International Journal of the Sociology of Language 69:19-31. https://doi.org/10.1515/ijsl.1988.69.19

Dow, James, Werner Enninger, and Joachim Raith (Eds.). 1994. Internal and External Perspectives on Amish and Mennonite Life 4. Essen, Germany: Unipress.

Dow, James, and Michele Wolff. 1997. “Introduction and Dedication.” Pp. 1-4 in Languages and Lives: Essays in Honor of Werner Enninger, edited by James Dow and Michele Wolff. New York, NY: Peter Lang Publishing, Inc.

Downing, Lara. 2015. "Dutchified English in an Ohio Mennonite Community.” MA thesis in Linguistics. Columbus, OH: Ohio State University.

Enninger, Werner. 1979a. "Language Convergence in a Stable Triglossia Plus Trilingualism Situation.” Pp. 43-63 in Anglistik Beiträge zur Fachwissenschaft und Fachdidaktik, edited by Frees. Münster, Germany: Regensberg.

—. 1979b. "Structural and Pragmatic Properties of Grooming and Garment Grammars.” Pp. 467-75 in Semiotic Unfolding, edited by T. Borbe. The Haag, Netherlands: Mouton.

—. 1980a. "Nonverbal Performatives: The Function of a Grooming and Garment Grammar in the Organization of Nonverbal Role-Taking and Role-Making in One Specific Trilingual Social Isolate.” Pp. 25-65 in Understanding Bilingualism, edited by Werner Hüllen. Frankfurt, Germany: Peter Lang. 
—. 1980b. "Syntactic Convergence in a Stable Triglossia Plus Trilingualism Situation in Kent County, Delaware, U.S.A.” Pp. 343-50 in Sprachkontackt und Sprachkonflikt, edited by P.H. Nelde. Wiesbaden, Germany: Franz Steiner.

- 1982. "The Semiotic Structure of Amish Folk Costume: Its Function in the Organization of Face-to-Face Interaction.” Pp. 86-123 in Multimedia Communication I, edited by Ernest and E.W.B. Hess-Lüttich. Tübingen, Germany: Gunter Narr.

—. 1984a. "Inferencing Social Structure and Social Processes from Nonverbal Behavior." American Journal of Semiotics 3(2):77-96. https://doi.org/10.5840/ajs19843222

- (Ed.). 1984b. Internal and External Perspectives on Amish and Mennonite Life 1. Essen, West Germany: Unipress.

-. 1984c. "Notes on the Expression Systems of Amish High German." Pp. 131-43 in Internal and External Perspectives on Amish and Mennonite Life 1, edited by Werner Enninger. Essen, West Germany: Unipress.

—. 1984d. "The Old Order Amish of Kent County, Delaware.” Pp. 80-95 in Papers from the Second Conference on German-Americana in the Eastern United States, Nov. 7-8, 1981, edited by M. Benjamin. Ontario.

- 1984e. "On the Role of Artifactual Signification and Communication in the Organization of Speaking.” Papers in Linguistics 17(1-4):53-88. https://doi.org/10.1080/08351818409389194

—. 1985. "Significant Silence among the Amish.” Pp. 149-59 in Third Conference on GermanAmericana in the Eastern United States, edited by Steven M. Benjamin and Michael Ritterson. Radford, VA: Radford University.

—. 1985. “Amish By-Names.” Names 33(4):243-58. https://doi.org/10.1179/nam.1985.33.4.243

—. 1986a. "The Ethnolinguistic Profile of the Old Order Amish in Transit and Transition." Pp. 197-215 in The Transit of Civilization from Europe to America: Essays in Honor of Hans Galinski, edited by W. Herget and K. Ortseifen. Tübingen, Germany: Gunter Narr.

-. 1986b. "Structural Aspects of Amish High German.” Pp. 61-105 in Studies on the Languages and the Verbal Behavior of the Pennsylvania Germans I, edited by Werner Enninger. Stuttgart, Germany: Franz Steiner Verlag Wiesbaden GMBH.

- 1986c. "The Theme of Ethnicity in the Literature of the Old Order Amish." Pp. 115-36 in Studies on the Languages and the Verbal Behavior of the Pennsylvania Germans I, edited by Werner Enninger. Stuttgart, Germany: Franz Steiner Verlag Wiesbaden GMBH.

—. 1987a. “Amish English: Dutchified?” Pp. 547-79 in Perspectives on Language in Performance: Studies in Linguistics, Literary Criticism, and Language Learning 1, to Honor Werner Hüllen on Occasion of His Birthday, 17 October 1987, edited by W. Lörscher and R. Schulze. Tübingen: Gunter Narr. 
—. 1987b. "On the Organization of Sign-Processes in an Old Order Amish (O.O.A.) Parochial School.” Research on Language and Social Interaction 21:143-70. https://doi.org/10.1080/08351818709389288

—. 1988a. "Coping with Modernity: Instrumentally and Symbolically, with a Glimpse at the Old Order Amish.” Brethren Life and Thought 33(Summer):154-70.

—. 1988b. "Coping with Modernity: Instrumentally and Symbolically, with a Glimpse at the Old Order Amish.” Pp. 16-51 in Internal and External Perspectives on Amish and Mennonite Life 3, edited by Werner Enninger, Joachim Raith, and Karl-Heinz Wandt. Essen, West Germany: Unipress.

—. 1988c. "On the Maintenance of German Language Varieties among the Old Order Amish." International Journal of the Sociology of Language 69:33-57.

- 1988d. "The Social Construction of Past, Present, and Future in the Written and Oral Texts of the Old Order Amish: An Ethno-Semiotic Approach to Social Belief.” Pp. 195-256 in Literary Anthropology, edited by Fernandos Poyatos. Amsterdam, Netherlands: Benjamins. https://doi.org/10.1075/z.36.14enn

—. 1991. "Focus on Silences across Cultures." Intercultural Communication Studies 1(1):1-38.

—. 1999. "Continuity and Innovation in the Bilingual Education among the Amish.” Pp. 21324 in The Construction of Knowledge, Learner Autonomy and Related Issues in Foreign Language Learning: Essays in Honour of Dieter Wolff, edited by Bettina Missler and Uwe Multhaup. Sonderdruck, Germany: Stauffenburg Verlag.

- 2002. Language and Language Use of the Amish and of Mennonite Groups of SwissGerman Origin. Essen, Germany: University of Essen.

Enninger, Werner, and Essen-Delaware Amish Project Team [34 contributors]. 1985. "The English of the Old Order Amish of Delaware: Phonological, Morpho-Syntactical, and Lexical Variation of English in the Language Contact Situation of a Trilingual Speech Community.” English World Wide 5(1):1-24. https://doi.org/10.1075/eww.5.1.02enn

Enninger, Werner, John Hostetler, Joachim Raith, and Karl-Heinz Wandt. 1989. "Rules of Speaking: The Case of the Old Order Amish.” Pp. 137-66 in Studies on the Languages and the Verbal Behavior of the Pennsylvania Germans II, edited by Werner Enninger, Joachim Raith, and Karl-Heinz Wandt. Stuttgart, Germany: Franz Steiner Verlag Wiesbaden GMBH.

Enninger, Werner, and Joachim Raith. 1981. "Linguistic Modalities of Liturgical Registers: The Case of the Old Order Amish (OOA) Church Service.” Yearbook of German-American Studies 16:115-29.

- 1982. An Ethnography-of-Communication Approach to Ceremonial Situations. A Study on Communication in Institutionalized Social Contexts: The Old Order Amish Church Service. Wiesbaden, Germany: Franz Steiner Verlag. 
- 1988. "Varieties, Variation, and Convergence in the Linguistic Repertoire of the Old Order Amish (OOA) in Kent County, Delaware.” Pp. 260-93 in Variation and Convergence: Studies in Social Dialectology, edited by Peter Auer and Aldo Di Luzio. Berlin, Germany: de Gruyter.

Enninger, Werner, Joachim Raith, and Karl-Heinz Wandt (Eds.). 1986. Internal and External Perspectives on Amish and Mennonite Life 2. Essen, West Germany: Unipress.

- (Eds.). 1988. Internal and External Perspectives on Amish and Mennonite Life 3. Essen, West Germany: Unipress.

Enninger, Werner, and Stephen Scott. 1985. "Kutschen Designs als Dinge und Zeichen.” Zeitschrift für Semiotik 7(4):367-82.

Enninger, Werner, and Karl-Heinz Wandt. 1979. "Social Roles and Language Choice in an Old Order Amish Community.” Sociologia Internationalis 17:111-33.

- 1982. "Pennsylvania German in the Context of an Old Order Amish Settlement: The Structural Instability of a Functionally Stable Variety.” Yearbook of German-American Studies 17:123-43.

—. 1984. "Language Ecology Revisited: From Language Ecology to Sign Ecology.” Pp. 29-50 in Studies in Language Ecology, edited by Werner Enninger and Lilith Haynes. Wiesbaden, Germany: Franz Steiner Verlag.

Fishman, Andrea 1988. Amish Literacy: What and How It Means. Pourtsmouth, NH: Heinemann.

Frey, J. William. 1945. “Amish ‘Triple-Talk’.” American Speech 20(2):85-98. https://doi.org/10.2307/487398

Gilland, David. 2017. “Anabaptist Influences on American Religious Pluralism.” American Studies Journal 62. (http://www.asjournal.org/63-2017/anabaptist-influences-americanreligious-pluralism/).

Hamilton, Jean, and Jana Hawley. 1999. "Sacred Dress, Public Worlds: Amish and Mormon Experience and Commitment.” Pp. 31-51 in Religion, Dress, and the Body, edited by Gabriella Lazaridis and Linda Arthur. New York, NY: Berg Publishing, Inc. https://doi.org/10.2752/9781847888839/RELDRBODY0007

Hurst, Charles, and David McConnell. 2010. An Amish Paradox: Diversity and Change in the World's Largest Amish Community Baltimore, MD: Johns Hopkins University Press.

Jolly, Natalie. 2014. "In This World but Not of It: Midwives, Amish, and the Politics of Power.” Sociological Research Online 19(2). https://doi.org/10.5153/sro.3294

Jolly, Natalie. 2017. "Birthing New Kinships: The Cross-Pollinating Potential of Amish Health Research.” Journal of Amish and Plain Anabaptist Studies 5(2):147-61.

Keiser, Steve Hartman. 2012. Pennsylvania German in the American Midwest. Durham, NC: Duke University Press. 
Loomis, Charles 1960. “The Old Order Amish as a Social System.” Pp. 212-48 in Social Systems: Essays on Their Persistence and Change. Princeton, NJ: D. Van Nostrand Company.

—. 1979. “A Farmhand's Diary.” Mennonite Quarterly Review 53(3):235-56.

Louden, Mark. 2016. Pennsylvania Dutch: The Story of an American Language. Baltimore, MD: Johns Hopkins University Press.

Olshan, Marc. 1981. "Modernity, the Folk Society, and the Old Order Amish: An Alternative Interpretation.” Rural Sociology 46(2):297-309.

—. 1984. "Subversive Religion: Basic Ecclesial Communities and the Old Order Amish.” Pp. 24-42 in Internal and External Perspectives on Amish and Mennonite Life 1, edited by Werner Enninger. Essen, West Germany: Unipress.

Raith, Joachim. 1980. “Types of Speech Communities and Language Use.” Pp. 131-46 in Understanding Bilingualism, edited by Werner Hüllen. Frankfurt, Germany: Peter Lang.

Reiling, Denise. 2002. “Managing the 'Marginalized’ Man: Fieldwork, Boundaries, and Ethics of Involvement.” Journal of Multicultural Nursing \& Health 8(3):15-20.

Reiling, Denise, and Michael Nusbaumer. 1997. "The Amish Drug Task Force: A Natural History Approach to the Construction of a Social Problem.” Journal of Multicultural Nursing \& Health 3(2):25-37.

Schuetz, Alfred. 1972[1932]. The Phenomenology of the Social World. London, England: Heinemann.

Scott, Stephen. 1981[1998]. Plain Buggies: Amish, Mennonite, and Brethren Horse-Drawn Transportation. Intercourse, PA: Good Books.

- 1988. The Amish Wedding and Other Special Occasions of the Old Order Communities. Intercourse, PA: Good Books.

—. 1992[2001]. Amish Houses \& Barns. Intercourse, PA: Good Books.

Scott, Stephen, and Kenneth Pellman. 1990[1999]. Living without Electricity. Intercourse, PA: Good Books.

Voelz, Sabrina. 2016. “Writing Life, Writing Back, and Writing Through: Saloma Miller Furlong's Why I Left the Amish: A Memoir and Bonnet Strings: An Amish Woman's Ties to Two Worlds.” Journal of Amish and Plain Anabaptist Studies 4(2):201-19. https://doi.org/10.18061/1811/79928

Wandt, Karl-Heinz. 1988. “A (Socio) Dialect-Geographical Investigation of Pennsylvania German: the Problem of Informant Selection.” Pp. 1-15 in Internal and External Perspectives on Amish and Mennonite Life 3, edited by Werner Enninger, Joachim Raith, and Karl-Heinz Wandt. Essen, West Germany: Unipress. 